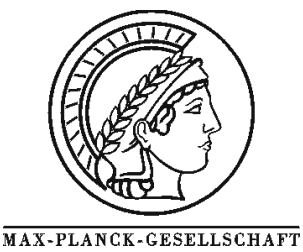

\title{
Structure and Reactivity of Iron Oxide Surfaces
}

\author{
Sh. K. Shaikhutdinov ${ }^{1}$, Y. Joseph, C. Kuhrs, W. Ranke* and W. Weiss \\ Department of Inorganic Chemistry, Fritz-Haber-Institute of the MPG, Faradayweg 4-6, 14195 Berlin, Germany \\ * Corresponding author: e-mail ranke@fhi-berlin.mpg.de, phone +49 308413 3192, fax +49 3084134401 \\ 1 \\ permanent address: Boreskov Institute of Catalysis, Novosibirsk, 630090 Russia
}

\begin{abstract}
Epitaxial films of different iron oxide phases and of potassium iron oxide were grown onto Pt(111) substrates and used for studying structure-reactivity correlations. The film morphologies and their atomic surface structures were characterized by scanning tunneling microscopy and low energy electron diffraction including multiple scattering calculations. The adsorption of water, ethylbenzene, and styrene was investigated by temperature programmed desorption and photoelectron spectroscopy. A dissociative chemisorption of water and a molecular chemisorption of ethylbenzene and styrene is observed on all oxides that expose metal cations in their topmost layers, whereas purely oxygen terminated $\mathrm{FeO}(111)$ monolayer films are chemically inert and only physisorption occurs. Regarding the technical styrene synthesis reaction which is performed over iron oxide based catalysts, we find a decreasing chemisorption strength of the reaction product molecule styrene if compared to ethylbenzene when going from $\mathrm{Fe}_{3} \mathrm{O}_{4}(111)$ over $\alpha-\mathrm{Fe}_{2} \mathrm{O}_{3}(0001)$ to $\mathrm{KFe}_{\mathrm{x}} \mathrm{O}_{\mathrm{y}}(111)$. Extrapolation of the adsorbate coverages to the technical styrene synthesis reaction conditions using the Langmuir isotherm for coadsorption suggests an increasing catalytic activity along the same direction. This result agrees with previous kinetic experiments performed at elevated gas pressures over the model systems studied here and over polycrystalline iron oxide catalyst samples. It indicates that the iron oxide surface chemistry does not change across the pressure-gap and that the model systems simulate technical styrene synthesis catalysts in a realistic way.
\end{abstract}

\section{Introduction}

Our understanding of the surface chemical and catalytic properties of metal oxides is still not well developed on a fundamental level. In order to obtain direct evidence on the role of atomic scale structural elements for the surface chemistry of metal oxides, single crystalline model systems with defined chemical compositions and surface structures including nonideal defects are needed. A systematic investigation of structure-reactivity correlations becomes possible if these parameters can be varied in a controlled manner, which turned out to be very difficult ${ }^{1}$. In a first step we combine the structural characterization of oxide surfaces with adsorption studies under ultrahigh vacuum conditions. In a second step the catalytic activities of the model systems are studied under real conditions. If the reaction kinetics at elevated gas pressures is in line with the elementary step kinetics determined under ultrahigh vacuum conditions, no major changes of the surface chemical properties can be assumed to occur across the pressure-gap. In this case surface science experiments can reveal relevant information on reaction meachanisms also under real conditions.

Iron oxides are used for catalyzing many reactions involving selective oxidations, dehydrogenations, oxo-dehydrogenations, and the water-gas shift reaction ${ }^{2}$. In particular, the dehydrogenation of ethylbenzene (EB) to styrene (St), a large scale sythesis reaction in chemical industry, is performed over iron oxide based catalysts in the presence of steam ${ }^{3,4}$. Kinetic experiments over polycrystalline samples revealed the promoter potassium to increase the catalyst activity by one order of magnitude ${ }^{5-7}$, and an active $\mathrm{KFeO}_{2}$ phase was found to form on the catalyst surface under reaction conditions ${ }^{8,9}$. The reaction rate depends on the adsorption-desorption equilibrium of the educt and product molecules $\mathrm{EB}$ and St, where the stronger adsorption of St leads to a site-blocking effect. In this work we study the adsorption of water, EB and St onto single crystalline films of different iron oxide phases and of potassium iron oxide with ultraviolett photoelectron spectroscopy (UPS) and thermal desorption spectroscopy (TDS), after the corresponding surface structures were investigated by scanning tunneling microscopy (STM) and low energy electron diffraction (LEED). These studies give insight into the styrene synthesis reaction mechanism and into structure-reactivity correlations of metal oxide materials in general. 
Since under thermodynamic equilibrium the stoichiometry of binary oxides is determined by the oxygen gas phase pressure and temperature ${ }^{10}$, heteroepitaxial film growth onto chemically inert substrates allows good control over the oxide stoichiometry. Well ordered $\mathrm{Fe}_{3} \mathrm{O}_{4}(111)$ and $\alpha-\mathrm{Fe}_{2} \mathrm{O}_{3}(0001)$ films were grown onto $\mathrm{Al}_{2} \mathrm{O}_{3}$ and $\mathrm{MgO}$ substrates by oxygenplasma assisted molecular beam epitaxy using different oxygen partial pressures and growth rates ${ }^{11,12}$. In the present paper, the film growth is accomplished by repeated cycles of iron deposition and subsequent oxidation followed by final oxidation treatments in different oxygen gas pressures. Well ordered $\mathrm{FeO}(111)$ monolayer films and 100-200 $\AA$ thick $\mathrm{Fe}_{3} \mathrm{O}_{4}(111)$ and $\alpha-\mathrm{Fe}_{2} \mathrm{O}_{3}(0001)$ films were prepared in this way. The growth and surface structures of these films was presented in previous work ${ }^{13-21}$ and is briefly summarized in section 3.1 . For the first time epitaxial potassium iron oxide films $\mathrm{KFe}_{\mathrm{x}} \mathrm{O}_{\mathrm{y}}(111)$ were prepared by depositing potassium onto $\mathrm{Fe}_{3} \mathrm{O}_{4}(111)$ films and subsequent annealing, as described in section 3.2.

For EB adsorbed on $\mathrm{Fe}_{3} \mathrm{O}_{4}(111)$ a strong interaction between the $\pi$-electron system of the phenyl ring with iron cations exposed on the regular surface areas was observed in previous UPS studies, whereas no chemical interaction occured on the oxygen-terminated $\mathrm{FeO}(111)$ surface ${ }^{22,23}$. An analog behavior is observed for water adsorbed onto these surfaces as discussed in section 3.3, where chemisorption reactivity again is found to be related to iron cations exposed on the regular oxide surface. In section 3.4 a decreasing chemisorption strength of the reaction product St if compared to EB is observed when going from $\mathrm{Fe}_{3} \mathrm{O}_{4}(111)$ over $\alpha-\mathrm{Fe}_{2} \mathrm{O}_{3}$ to $\mathrm{KFe}_{\mathrm{x}} \mathrm{O}_{\mathrm{y}}(111)$. It is discussed why this result agrees with catalytic activities of these model sytems ${ }^{24}$ and of polycrystalline iron oxide samples ${ }^{5,6}$ observed in previous reaction experiments at elevated gas pressures.

\section{Experimental \\ 2.1 Instrumentation}

The experiments were performed in three separate chambers described in detail in ref.[25], which all had base pressures below $1 \times 10^{-10}$ mbar and contained standard facilities for sample cleaning. The STM and TDS chambers were equiped with backview LEED optics and cylindrical mirror analyzers for Auger electron spectroscopy measurements (AES), which were carried out at $3 \mathrm{kV}$ primary beam energy, a beam current of $\sim 70 \mu \mathrm{A} / \mathrm{cm}^{2}$ and a modulation voltage of $\mathrm{V}_{\mathrm{pp}}=10 \mathrm{~V}$. The UPS chamber contained a Helium resonance lamp (He I line $21.2 \mathrm{eV}$, He II line $40.8 \mathrm{eV}$ ), a double pass cylindrical mirror analyzer and a high resolution spot profile analysis LEED system designed by Henzler ${ }^{26}$. For UPS measurements the direction of light incidence was normal to the analyser axis. As a result, the spectra were averaged over a large range of escape angles.

Each chamber contained a sample transfer system and a full rotatable off-axis manipulator with identical sample heatingcooling stations, where a Pt(111) crystal mounted onto a sample holder can be heated by electron bombardment from the back and cooled by a liquid nitrogen reservoir. A chromel-alumel thermocouple was spotwelded onto the edge of the crystal for temperature control. High pressure oxidation treatments were performed in preparation cells that can be completely separated from the analysis chamber by a gate valve after the sample transfer. Temperatures up to $1100 \mathrm{~K}$ could be reached in oxygen pressures up to 1 mbar using a 250 Watt halogen lamp radiation heater located in front of the sample.

The STM experiments were performed with a commercial instrument mounted horizontally on a $150 \mathrm{~mm}$ flange, into which the sample holder can be transferred from the off-axis manipulator. All measurements were done at room temperature in the constant current mode, after electrochemically etched tungsten tips were cleaned in-situ by electron bombardment. Calibration of the scanner was performed on a $\mathrm{Si}(111)-(7 \times 7)$ surface. Image processing of the experimental data included background subtraction and smoothing procedures. All TDS experiments were performed with heating rates of $5 \mathrm{~K} / \mathrm{s}$ after gas adsorption at sample temperatures of $\mathrm{T}=100 \mathrm{~K}$. The exposures are given in Langmuirs $\left(1 \mathrm{~L}=1.33 \times 10^{-6} \mathrm{mbar}\right)$ after correcting for the ionization probabilities of EB and St, which are about 7 times higher than for $\mathrm{N}_{2}{ }^{27}$. High purity EB and St and triple destilled water were dosed via leak valves into the UHV chambers. Before that the EB and St were filled under $\mathrm{N}_{2}$ atmosphere into a small glass bulb containing an activated molecular sieve to reduce possible contaminations by water.

\subsection{Preparation of iron oxide films}

A clean $\mathrm{Pt}(111)$ surface is prepared by numerous cycles of argon ion bombardment $(1 \mathrm{keV})$ and subsequent annealing to $1300 \mathrm{~K}$, until it exhibited a sharp LEED pattern and no contamination signals in AES. Onto this surface iron was evaporated with an electron beam assisted evaporator or by resistively heating a tungsten wire with an iron wire wrapped around it. As described in more detail in ref. [19] 1-2 monolayer thick $\mathrm{FeO}(111)$ films and 100-200 $\AA$ thick $\mathrm{Fe}_{3} \mathrm{O}_{4}(111)$ films were prepared by repeated cycles of iron deposition at room temperature and subsequent oxidation for about 2 min at temperatures around $1000 \mathrm{~K}$ in $10^{-6}$ mbar oxygen partial pressure. The $\mathrm{Fe}_{3} \mathrm{O}_{4}(111)$ films were transformed into $\alpha-\mathrm{Fe}_{2} \mathrm{O}_{3}(0001)$ films by an oxidation treatment for 10-15 min in oxygen partial pressures above $10^{-3}$ mbar at temperatures around $\mathrm{T}=1100 \mathrm{~K}$. Potassium iron oxide films were prepared by deposition of potassium from a SAES getter source onto $\mathrm{Fe}_{3} \mathrm{O}_{4}(111)$ films at room temperature and subsequent annealing to $1000 \mathrm{~K}$ in vacuum or in $10^{-6}$ mbar oxygen. 


\section{Results and Discussion 3.1 Growth and surface structures of iron oxide films}

Fig. 1a displays a $55 \times 55 \AA^{2}$ atomic resolution STM image of the first iron oxide layer grown onto the Pt(111) surface. A hexagonal lattice of protrusions with a 3.1 A periodicity and a moiré superstructure with a $25 \AA$ periodicity can be seen. STM image simulations performed by Galloway et al. ${ }^{15}$ revealed the atomic protrusions to occur at oxygen atom positions located in the topmost layer of this film. Fig. 1c depicts a schematic model, which consists of a hexagonal close-packed iron-oxygen bilayer with oxygen located on top. This $\mathrm{FeO}(111)$ bilayer is laterally expanded to a lattice constant of $\mathrm{aFeO}=3.11 \AA$ (the value in bulk $\mathrm{FeO}$ is $3.04 \AA$ ) and rotated by $\alpha=1.3^{\circ}$ against the $\operatorname{Pt}(111)$ surface lattice. As explained in detail in ref. [18] the $12 \%$ lattice mismatch creates the $\mathrm{FeO}(111)$ coincidence moiré superstructure visible in the STM image in Fig. 1a. The LEED pattern shown in Fig. $1 \mathrm{~b}$ exhibits main diffraction spots that correspond to the lattice constant of $\mathrm{aFeO}^{=3.1} \AA$ and that are surrounded by satellite spots which are created by double diffraction between the $\operatorname{Pt}(111)$ surface and the $\mathrm{FeO}(111)$ overlayer. This $\mathrm{FeO}(111)$ bilayer structure terminated by an outermost close-packed oxygen layer was also deduced from photoelectron diffraction experiments. There, a strongly reduced iron-oxygen interlayer distance of $0.68 \AA$ (the (111) interlayer distance in bulk $\mathrm{FeO}$ is $1.25 \AA$ ) which goes along with the lateral lattice expansion was obtained ${ }^{28}$.

The first $\mathrm{FeO}(111)$ layer completely wets the platinum substrate. Depending on the exact oxidation temperature a second $\mathrm{FeO}(111)$ layer grows, followed by the formation of three-dimensional $\mathrm{Fe}_{3} \mathrm{O}_{4}(111)$ islands ${ }^{19}$. These islands eventually coalesce and form closed $\mathrm{Fe}_{3} \mathrm{O}_{4}(111)$ films that are at least $100 \AA$ thick. They consist of hexagonally shaped crystallites with lateral dimensions of about $1000 \AA$ as depicted in Fig. 6a. These crystallites are atomically flat with a few monoatomic steps and somewhat higher step densities at the crystallite edges. After a final oxidation treatment at $1000 \mathrm{~K}$ the vertical roughness of the $\mathrm{Fe}_{3} \mathrm{O}_{4}$ (111) films ranges between 30 and $100 \AA$ on a length scale of $1 \mu \mathrm{m}$, and one defined surface structure is formed. It exhibits atomic resolution STM images as shown in Fig. 2a, where a hexagonal lattice of protrusions with a $6 \AA$ periodicity and randomly distributed missing protrusions can be seen. These images are observed both for positive and negative bias voltages applied to the sample. The LEED pattern of these films is shown in Fig. 2b, it corresponds to a hexagonal surface unit cell with a lattice constant of $6 \AA$.

$\mathrm{Fe}_{3} \mathrm{O}_{4}$ magnetite crystallizes in the cubic inverse spinel structure where the oxygen anions form a close-packed fcc sublattice with tetrahedrally and octahedrally coordinated $\mathrm{Fe}^{2+}$ and $\mathrm{Fe}^{3+}$ cations located in the interstitial sites ${ }^{29,30}$. The interatomic distance within the close-packed oxygen (111) planes is $2.96 \AA$. Since not all sites are occupied within the iron (111) planes a two-dimensional hexagonal unit cell with a lattice constant of $5.92 \AA$ is formed as observed by STM and LEED. The $\mathrm{Fe}_{3} \mathrm{O}_{4}(111)$ surface structure was determined by a full dynamical LEED intensity analysis and is displayed in a top view in Fig. $2 c^{16,21}$. It exposes $1 / 4$ monolayer of iron cations that would be tetrahedrally coordinated in the bulk, located over a closepacked oxygen layer underneath. The first four interlayer spacings were found to strongly relax. Based on this result we assign the protrusions in the atomic resolution STM image to the topmost layer iron cation positions. This interpretation is supported by recent ab-initio calculations performed for this surface termination. They revealed a high electron density of states located just above and below the Fermi level, which is related to Fe3d orbitals of the top layer iron atoms ${ }^{31}$. The missing protrusions in the STM image in Fig. 2a represent the most abundant type of point defects on these surfaces, and they are attributed to iron vacancies in the topmost layer. This interpretation was confirmed by dynamical LEED calculations, where different types of vacancies were tested with a LEED program that simulates surface point defects in a random distribution. When analyzing LEED data of surfaces with high defect concentrations a considerable improvement of the Rfactor $(12 \%)$ was achieved only for iron vacancy defects.

$\alpha-\mathrm{Fe}_{2} \mathrm{O}_{3}(0001)$ films were prepared by oxidizing $\mathrm{Fe}_{3} \mathrm{O}_{4}(111)$ films at oxygen pressures above $10^{-3}$ mbar. $\alpha-\mathrm{Fe}_{2} \mathrm{O}_{3}$ hematite crystallizes in the corundum structure, where the oxygen anions form an hcp sublattice with octahedrally coordinated $\mathrm{Fe}^{3+}$ cations located in the interstitials ${ }^{30}$. Fig. $3 c$ depicts a top view onto an unrecostructed $\alpha-\mathrm{Fe}_{2} \mathrm{O}_{3}(0001)$ surface terminated by an outermost iron layer. The oxygen anion positions within the close-packed (0001) planes slightly deviate from an ideal hexagonal arrangement leading to an average oxygen-oxygen interatomic distance of $2.91 \AA$. Within the iron (0001) planes only $1 / 3$ of all sites are occupied leading to a two-dimensional hexagonal unit cell with a lattice constant of $5.03 \AA$. Fig. 3a shows an atomic resolution STM image of a surface prepared in $10^{-3}$ mbar oxygen, where a hexagonal lattice of protrusions with a $5 \AA$ periodicity can be seen. The LEED pattern in Fig. 3b corresponds to a hexagonal surface unit cell with a lattice constant of $5 \AA$. We attribute the protrusions in the STM image to the topmost iron atom positions on an $\alpha-\mathrm{Fe}_{2} \mathrm{O}_{3}(0001)$ surface as depicted in Fig.3c. Recent ab-initio calculations predicted an iron-terminated $\alpha-\mathrm{Fe}_{2} \mathrm{O}_{3}(0001)$ surface structure to be stable in low oxygen pressure environments and an oxygen-terminated surface structure to be stable in high oxygen pressures environments ${ }^{32}$. As described in ref. [20] we observe coexisting iron-terminated and oxygen-terminated surface domains after preparations in oxygen pressures between $10^{-4}$ and $10^{-1}$ mbar. When prepared in $10^{-5}$ mbar oxygen the iron terminated surface structure depicted in Fig. $3 \mathrm{c}$ is formed on the entire sample. All adsorption experiments presented in this paper were performed on this surface.

\subsection{Formation and surface structure of potassium iron oxide films}


Potassium iron oxide films were prepared by deposition of approximately $5 \mathrm{ML}$ of potassium at $300 \mathrm{~K}$ onto $\mathrm{Fe}_{3} \mathrm{O}_{4}(111)$ films and subsequent annealing in vacuum. We monitored the reaction between the deposited $\mathrm{K}$ and the oxide film by stepwise annealing to increasing temperatures for 10-15 seconds each. After cooling down the sample Auger spectra were taken and the surface composition was determined using AES sensitivity factors from ref. [33]. The resulting temperature dependence of the surface composition is shown in Fig. 4a. The K concentration decreases considerably between 300 and 450 $\mathrm{K}$, accompanied by a corresponding increase of the $\mathrm{Fe}$ and $\mathrm{O}$ concentrations. This is due to thermal desorption of $\mathrm{K}$ within this temperature range as observed in the desorption trace depicted in (b), which was measured after room temperature deposition of the same amount of $\mathrm{K}$ as in (a). With further increasing temperature the $\mathrm{K}$ concentration decreases only slightly until it drops more rapidly beyond $700 \mathrm{~K}$, but no further desorption of potassium is observed within this temperature range. From this we conclude that potassium diffuses into the bulk where it might undergo a solid state reaction with the iron oxide. At temperatures around $970 \mathrm{~K}$ a composition $\mathrm{KFe}_{\mathrm{x}} \mathrm{O}_{\mathrm{y}}$ with $\mathrm{x} \approx 1$ and $\mathrm{y} \approx 2$ is deduced from the Auger spectrum shown in Fig. 5 , which is close to the stoichiometry of the $\mathrm{KFeO}_{2}$ compound. At this point the film surface has become well-ordered and displays the LEED pattern depicted in Fig. 7a, which corresponds to a $(2 \times 2)$ superstructure with respect to $\mathrm{Fe}_{3} \mathrm{O}_{4}(111)$ $(1 \times 1)$.

Fig. $4 \mathrm{c}$ shows a thermal desorption trace measured for a $\mathrm{KFe}_{\mathrm{x}} \mathrm{O}_{\mathrm{y}}(111)$ film which exhibits the characteristc $(2 \times 2)$ LEED pattern. The film is thermally stable up to $1000 \mathrm{~K}$ when potassium starts to desorb first. Three $\mathrm{K}$ desorption peaks located at at $1115 \mathrm{~K}, 1165 \mathrm{~K}$ and $1260 \mathrm{~K}$ can be seen, the latter two coincide with maxima in the Fe and $\mathrm{O}$ desorption traces. For clean $\mathrm{Fe}_{3} \mathrm{O}_{4}$ and $\alpha-\mathrm{Fe}_{2} \mathrm{O}_{3}$ films only one broad desorption signal with a maximum around $1300 \mathrm{~K}$ is observed during thermal decomposition (not shown here). The initial desorption starting at $1000 \mathrm{~K}$ can be attributed to potassium at the surface and in the subsurface region, where it has accumulated and from where it can diffuse quickly to the surface at these temperatures. The depletion of $\mathrm{K}$ in the subsurface region might be accompanied by a decomposition of a ternary $\mathrm{K}-\mathrm{Fe}-\mathrm{O}$ compound into $\mathrm{K}$ and $\mathrm{Fe}_{3} \mathrm{O}_{4}$. This decomposition does not get completed during the temperature ramp leading to a common desorption maximum for potassium, iron and oxygen at $1165 \mathrm{~K}$, which indicates decomposition and desorption of the ternary compound phase left in the subsurface region. The desorption maximum at $1260 \mathrm{~K}$ is dominated by iron and oxygen with a small potassium contribution only, which indicates the decomposition and desorption of the $\mathrm{Fe}_{3} \mathrm{O}_{4}$ bulk phase.

The surface structure and morphology of the $\mathrm{KFe}_{\mathrm{X}} \mathrm{O}_{\mathrm{y}}(111)$ film was studied by STM. Fig. 6 displays $5000 \times 5000 \AA^{2}$ images of the original $\mathrm{Fe}_{3} \mathrm{O}_{4}(111)$ film (a) and of the $\mathrm{KFe}_{\mathrm{x}} \mathrm{O}_{\mathrm{y}}(111)$ film (b). The $\mathrm{KFe}_{\mathrm{x}} \mathrm{O}_{\mathrm{y}}(111)$ film forms small terraces with predominantly triangular shapes, and it is much rougher if compared to the $\mathrm{Fe}_{3} \mathrm{O}_{4}(111)$ film. This surface roughening is probably caused by the diffusion of $\mathrm{K}$ into the bulk of the film. However, the film surface is well ordered and exhibits the $(2 \times 2)$ LEED pattern depicted in Fig. 7a, which corresponds to a hexagonal unit cell with a lattice constant of $12 \AA$. This unit cell is also resolved in the STM image shown in Fig. $7 \mathrm{~b}$.

Since K diffuses into the bulk, the formation of a ternary compound seems quite possible. The only stable ternary K-Fe-O phase which is compatible with the surface composition measured by AES is $\mathrm{KFeO}_{2}{ }^{34}$. Due to its orthorhombic crystal structure, $\mathrm{KFeO}_{2}$ contains no hexagonal lattice planes. Therefore, only a strongly distorted $\mathrm{KFeO}_{2}$ lattice could form the observed $(2 \times 2)$ superstructure with respect to $\mathrm{Fe}_{3} \mathrm{O}_{4}(111)-(1 \times 1)$, which seems unlikely. Potassium may also substitute iron atoms in the $\mathrm{Fe}_{3} \mathrm{O}_{4}$ lattice in variable concentrations. The strain produced in such a solid solution while maintaining the pseudomorphic relationship to the $\mathrm{Fe}_{3} \mathrm{O}_{4}(111)$ substrate may limit the maximum potassium concentration. Indeed, Auger measurements performed on films prepared after initial deposition of different amounts of $\mathrm{K}$ and different numbers of annealing cycles reveal varying $\mathrm{KFe}_{\mathrm{x}} \mathrm{O}_{\mathrm{y}}$ compositions with $\mathrm{x} \approx 1.1-0.9$ and $\mathrm{y} \approx 1.3-2$. But since AES averages over the electron escape depth of $10-20 \AA$, these compositions may result from potassium concentrations that vary with the distance from the surface.

The atomic resolution STM image in Fig. $7 \mathrm{~b}$ reveals two different structures. Here they are separated by a step $2.5 \AA$ high, but in other images they are also observed on the same level. Both exhibit hexagonal lattices of protrusions with a $12 \AA$ periodicity, but the half-width of the protrusions on the upper terrace is about $6 \AA$, whereas that on the lower terrace is about $4 \AA$. Also, the upper terrace looks clean while the lower one is covered by adsorbate like species, which suggests different chemical properties for these two surface structures. We assign the atomic protrusions to potassium atom positions in the topmost layer of this film. This is in line with other studies where alkali metals were found to form the uppermost surface layers ${ }^{35}$. 36 . Also alkali metals adsorbed on metal and metal-oxide surfaces were imaged as protrusions with $\mathrm{STM}^{37-39}$, in agreement with theoretical calculations ${ }^{40}$. X-ray diffraction and ion scattering experiments are planned in order to further clarify the surface structure of these films, the interpretation of the STM images and the question about the formation of a ternary $\mathrm{K}-\mathrm{Fe}-\mathrm{O}$ compound phase.

Before and after performing adsorption and catalysis experiments the $\mathrm{KFe}_{\mathrm{X}} \mathrm{O}_{\mathrm{y}}(111)$ films were cleaned by flashing to $900 \mathrm{~K}$ in $10^{-6}$ mbar oxygen. STM, LEED and AES showed no changes of the surface structure and composition after this treatment. 


\subsection{Active sites for water chemisorption}

As discussed in section 3.1, the surface of the $\mathrm{FeO}(111)$ film is oxygen-terminated whereas the surface of the $\mathrm{Fe}_{3} \mathrm{O}_{4}(111)$ film exposes $1 / 4$ monolayer of iron cations over a close-packed oxygen layer underneath. Fig. 8 shows thermal desorption spectra after exposing both surfaces at $100 \mathrm{~K}$ to increasing amounts of water. On $\mathrm{FeO}(111)$ a desorption maximum at $170 \mathrm{~K}$ is observed first, which shifts to $164 \mathrm{~K}$ as the exposure increases to $0.3 \mathrm{~L}$. This signal is attributed to physisorbed water labeled $\beta$. With further increasing exposure the desorption traces form a common leading edge which is characteristic for zero order desorption of condensed ice multilayers labeled $\alpha$. On $\mathrm{Fe}_{3} \mathrm{O}_{4}(111)$ a desorption maxiumum around $280 \mathrm{~K}$ is observed first which is attributed to chemisorbed water labeled $\gamma$. With increasing exposure a physisorbed $\beta$ signal at $190 \mathrm{~K}$ evolves, followed by the ice multilayer signal $\alpha$. No species other than water desorb, especially no hydrogen. The absence of a chemisorption signal on $\mathrm{FeO}(111)$ but not on $\mathrm{Fe}_{3} \mathrm{O}_{4}(111)$ indicates a specific chemical interaction related to the iron cations exposed on the $\mathrm{Fe}_{3} \mathrm{O}_{4}(111)$ surface.

The TDS spectra were taken after exposing the sample to defined amounts of water at a temperature low enough to prevent desorption after pumping off the water vapor. Because of low mobilities of the adsorbed species at this temperature the equilibrium may not be reached, and different adsorption states may not be occupied strictly sequentially or even incompletely in case of activated adsorption. We have taken UP spectra under conditions of dynamic adsorption-desorption equilibrium. Water was admitted at a constant vapor pressure and spectra were taken at different sample temperatures after establishment of the corresponding equilibrium coverages, which took up to 6 minutes at maxiumum for the chemisorbed species. Under such conditions the adsorption of the different species occured strictly sequentially. UPS turned out to be a non-destructive technique and reveals both the nature of the adsorbate species and their coverages. It further allows to determine work function changes which yields information on the adsorbate orientation.

Fig. 9a presents a sequence of UP spectra taken from the $\mathrm{FeO}(111)$ monolayer film at a pressure $\mathrm{p}\left(\mathrm{H}_{2} \mathrm{O}\right)=1 \times 10^{-8}$ mbar upon stepwise decreasing the sample temperature from $307 \mathrm{~K}$ (no adsorption) to $137 \mathrm{~K}$ (beginning condensation). Significant adsorption starts below about $180 \mathrm{~K}$. Below $-6 \mathrm{eV}$ with respect to the Fermi level, the intensity increase due to adsorbateinduced emission dominates the spectral changes whereas above $-6 \mathrm{eV}$ attenuation of the substrate emission is dominating. In order to deduce the adsorbate coverage $\Theta$ we use the attenuation factor AF, which was determined near the Fermi level $\mathrm{EF}_{\mathrm{F}}$ where no adsorbate emission features exist. According to a Lambert-Beer absorption law, the adsorbate thickness $d$ in units of the electron escape depth $1_{\mathrm{e}}$ is given by $\mathrm{d} / \mathrm{l}_{\mathrm{e}}=\ln (1 / \mathrm{AF}) \propto \Theta$. The escape depth is given by $\mathrm{l}_{\mathrm{e}}=\lambda_{\mathrm{e}} \cos \alpha$ with $\lambda_{\mathrm{e}}$ the electron mean free path and $\alpha$ the mean escape angle ( $42^{\circ}$ for the cylindrical mirror analyser used here). For $\mathrm{E}_{\mathrm{kin}} \approx 20 \mathrm{eV}$ (with respect to $E_{F}$ ) $\lambda_{e}$ is between 3 and $10 \AA^{41}$ and the value $d / l_{\mathrm{e}}=1$ (corresponding to $A F=0.37$ ) should correspond to an adsorbate

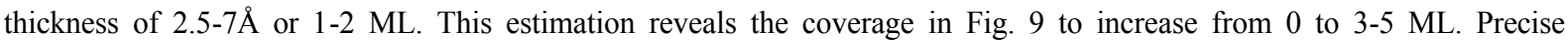
coverages will be deduced from comparisons with adsorption models on the different oxide surfaces.

From incremental difference spectra (difference between subsequent spectra), changes in the adsorbate spectra can be seen which occur when an adsorbate species has saturated and a new species starts to form on top. This happens at coverages corresponding to the two dotted spectra being the lower ones in the range below $-6 \mathrm{eV}$ in Fig. 9a. The highest dotted spectrum corresponds to condensation and does not saturate. The spectra in Fig. $9 \mathrm{~b}$ represent the differences between the dotted spectra in Fig. 9a and the properly attenuated clean substrate spectrum. They reflect two saturated species labeled $\beta_{1}$ and $\beta_{2}$ which form sequentially, followed by the condensate spectrum $\alpha$, which does not represent saturation. The work function change is given by the shift of the low energy onset of the spectra in Fig. 9a. It decreases by $0.82 \mathrm{eV}$ for saturation of $\beta_{1}$ and further by $0.33 \mathrm{eV}$ upon saturation of $\beta_{2}$. Condensation does not change the work function further.

The spectra in Fig. $9 \mathrm{~b}$ are referenced to the vacuum level $\mathrm{E}_{\mathrm{vac}}$ so that comparison with the orbital positions of gas phase water $^{42}$ is possible. The general spectral shapes of the three species are similar and correspond to the spectrum of gaseous water, shifted by different relaxation shifts $\Delta \mathrm{E}_{\mathrm{R}}=1.8,1.5$ and $1.3 \mathrm{eV}$ for the $\beta_{1}, \beta_{2}$ and $\alpha$ species (taken from the average shift of the $1 b_{1}$ and $1 b_{2}$ orbitals). We therefore conclude that all species represent molecular water. The $\beta_{1}$ species saturates at a coverage corresponding to $\mathrm{d} / \mathrm{l}_{\mathrm{e}}=0.55 \pm 0.03$ and exhibits relative peak positions that agree well with those of gaseous water. Therefore, we ascribe it to physisorbed water monomers. From the work function decrease we conclude that the molecules are oriented with their oxygen atoms towards the substrate. Because they are weakly bound, they may be mobile and form a two-dimensional lattice gas as interpreted for similar species observed on other surfaces ${ }^{43,44}$. All orbitals of the $\beta_{2}$ species are shifted and broadened with respect to $\beta_{1}$, and the $3 \mathrm{a}_{1}$ emission contains contributions from two peaks as indicated by the bars in Fig. 9b. This is typical for hydrogen-bonded aggregates with two kinds of water molecules in different bonding configurations ${ }^{43}, 45,46$, where one acts as proton donor and the other as proton acceptor. The $\beta_{2}$ species saturates at $\mathrm{d} / \mathrm{l}_{\mathrm{e}}=1.3 \pm 0.2$, more than twice that of the $\beta_{1}$ species. We ascribe it to a physisorbed water bilayer as identified previously on several metal surfaces ${ }^{47}$. For the condensed $\alpha$ species the position of the $3 a_{1}$ emission relative to the $1 b_{2}$ and $1 b_{1}$ orbitals is similar to that of the $\beta_{2}$ species. In the bulk of a well crystallized ice film all molecules are equivalent and no splitting of the $3 \mathrm{a}_{1}$ orbital is expected. The broadening of the $3 \mathrm{a}_{1}$ signal in Fig. $9 \mathrm{~b}$ is caused by differently coordinated water molecules at the surface and at the interface to the substrate, since the ice layer was only about two bilayers thick. 
In contrast to the general tendency of adsorbed water to form aggregates already at small coverages ${ }^{47}$, water monomers first physisorb on $\mathrm{FeO}(111)$ without aggregation. Although the interaction with the substrate is weak $(\approx 50 \mathrm{~kJ} / \mathrm{mol}$ desorption energy as determined from the TDS data), it appears to be strong enough to overbalance the energy gain from hydrogen bonding in aggregates. It saturates at less than half the coverage of the $\beta_{2}$ bilayer, which would be compatible with an $(\sqrt{3} \mathrm{x} \sqrt{3} \mathrm{R}) \mathrm{R} 30^{\circ}$ adsorbate structure referred to $\mathrm{FeO}(111)-(1 \times 1)$. But no corresponding LEED pattern was observed, possibly due to a high mobility of the adsorbed species. The work function decrease implies adsorption with the oxygen atom and its lone pair orbital oriented towards the substrate, which is quite unexpected for an oxygen terminated surface. The reason may be that the electronic structure of the $\mathrm{FeO}(111)$ monolayer film deviates from that of the corresponding bulk material. Indeed, the Fe-O interlayer distance is only $0.68 \AA^{28}(1.25 \AA$ in bulk FeO), so that water molecules adsorbed onto threefold hollow sites of the outermost oxygen layer may "feel" the acidic character of the iron atoms underneath, resulting in the adsorption geometry we propose for the monomeric $\beta_{1}$ water species.

Fig. 10a presents UP spectra for water adsorbed on the $\mathrm{Fe}_{3} \mathrm{O}_{4}(111)$ surface under the same equilibrium conditions as in Fig. 9a. Here the adsorption starts already at $350 \mathrm{~K}$, and three sequentially adsorbing species can be distinguished. Their spectra in Fig. $10 \mathrm{~b}$ are formed from the differences between the dotted saturation curves in (a). The first species labeled $\gamma$ saturates at

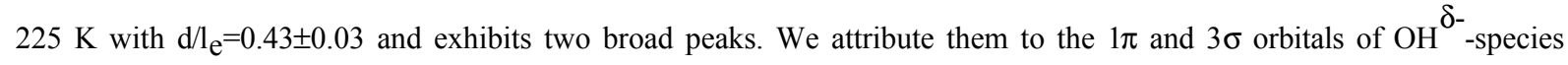
formed by dissociation of water into $\mathrm{OH}^{\delta-}+\mathrm{H}{ }^{+}{ }_{48}$, as observed on many other metal oxide surfaces ${ }^{49-54}$. The work function decreases by $0.75 \mathrm{eV}$, indicating that $\mathrm{OH}^{\delta}{ }^{-}$species are adsorbed with the oxygen atom oriented towards the surface. The features between -5 and $-10 \mathrm{eV}$ below $\mathrm{E}_{\mathrm{vac}}$ are probably due to adsorbate induced changes of the substrate emission and to emission from the coadsorbed atomic hydrogen.

The saturation coverage (in terms of $\mathrm{d} / \mathrm{l}_{\mathrm{e}}$ ) of dissociatively chemisorbed water is about $1 / 3$ of the water bilayer $\beta_{2}$ saturation coverage on $\mathrm{FeO}(111)$. This is slightly less than the monomeric $\beta_{1}$ water layer thereon, which is too high to be explained by defect related chemisorption. Therefore, regular surface sites must be responsible for the chemisorption. On films with higher surface defect concentrations, as estimated from the spot widths and background intensities in the LEED pattern, we observe lower saturation coverages. Since the dominant type of point defects on $\mathrm{Fe}_{3} \mathrm{O}_{4}(111)$ are iron vacancies, this observation clearly indicates that iron cations exposed on the surface are responsible for the dissociative chemisorption of water into $\mathrm{OH}^{\delta-}$ and $\mathrm{H}^{\delta+}$. The $\mathrm{OH}^{\delta-}$ group is adsorbed onto an acidic $\mathrm{Fe}$ site and $\mathrm{H}^{\delta+}$ onto a neighboring basic oxygen site. On low defect density films the saturation coverage of $\mathrm{OH}^{\delta-}$ and $\mathrm{H}^{\delta+}$ should be equal to the iron surface density, i.e. $3.3 \times 10^{14} \mathrm{~cm}^{-2}$. This corresponds to $31 \%$ of the density of water molecules in an ideal bilayer $\left(10.6 \times 10^{14} \mathrm{~cm}^{-2}\right.$ for an adsorbed bilayer, slightly less than the value $11.2 \times 10^{14} \mathrm{~cm}^{-2}$ for the bilayer density in thick ice ${ }^{47}$ ). Taking the experimental error into account, the observed ratio of the saturation coverages for the chemisorbed $\gamma$ layer on $\mathrm{Fe}_{3} \mathrm{O}_{4}(111)\left(\mathrm{d} / \mathrm{l}_{\mathrm{e}}=0.43 \pm 0.03\right)$ and the physisorbed bilayer $\beta_{2}\left(\mathrm{~d} / \mathrm{e}^{=1.3 \pm 0.2)}\right.$ on $\mathrm{FeO}(111)$ is $0.33 \pm 0.08$, which represents a remarkable agreement and strongly supports the adsorption model.

The saturation temperature, spectral shape, and orbital binding energies of the second species formed on $\mathrm{Fe}_{3} \mathrm{O}_{4}(111)$ are similar to the $\beta_{1}$ species on $\mathrm{FeO}(111)$ and thus corresponds to monomeric physisorbed water. It saturates at a total coverage $\mathrm{d} / \mathrm{l}_{\mathrm{e}}=0.86 \pm 0.03$ (for $\gamma+\beta_{1}$ ), which is exactly twice that of the $\gamma$-species. This is consistent with a fully occupied first adsorbate layer consisting of equal amounts of the $\gamma$ and $\beta_{1}$ species, i.e. of $\mathrm{OH}^{\delta-}, \mathrm{H}^{\delta+}$ and coadsorbed monomeric $\mathrm{H}_{2} \mathrm{O}$. At higher coverages water condenses on top of this $\gamma+\beta_{1}$ layer.

To summarize, on both surfaces a sequential adsorption of three different species is observed. Their saturation coverages correlate quantitatively with the respective surface structures. The oxygen-terminated $\mathrm{FeO}(111)$ surface is chemically inert and a physisorption of water monomers is observed, followed by the formation a hydrogen bonded bilayer and finally by condensation of ice. On the iron-terminated $\mathrm{Fe}_{3} \mathrm{O}_{4}(111)$ surface a dissociative chemisorption of water occurs, which was also observed on (0001) and (012) surfaces of $\alpha-\mathrm{Fe}_{2} \mathrm{O}_{3}{ }^{55,56}$. On $\mathrm{Fe}_{3} \mathrm{O}_{4}(111)$ the chemisorption is not related to surface defects but occurs on regular surface areas. After saturation of the chemisorbed species, water monomers get coadsorbed followed by condensation of ice. The dissociative chemisorption is caused by the cooperative action of neighboring acidic iron and basic oxygen sites, which are exposed on the surface in a geometry that allows the adsorption of $\mathrm{OH}^{\delta-}$ and $\mathrm{H}^{\delta+}$ species after the dissociation of a water molecule. These findings agree with a previous study, where a specific chemical interaction between surface iron cations and the $\pi$-electron system of EB was observed ${ }^{23}$, since EB is molecularly chemisorbed on the ironterminated $\mathrm{Fe}_{3} \mathrm{O}_{4}(111)$ surface but not on the oxygen-terminated $\mathrm{FeO}(111)$ surface.

\subsection{Adsorption of ethylbenzene and styrene onto $\mathrm{Fe}_{3} \mathrm{O}_{4}(111), \alpha-\mathrm{Fe}_{2} \mathrm{O}_{3}(0001)$ and $\mathrm{KFe}_{\mathrm{x}} \mathrm{O}_{\mathrm{y}}(111)$}

The dehydrogenation of ethylbenzene (EB) to styrene (St) is performed over iron oxide catalysts promoted with potassium. We studied the adsorption of the EB educt and St product molecules onto the $\mathrm{Fe}_{3} \mathrm{O}_{4}(111), \alpha-\mathrm{Fe}_{2} \mathrm{O}_{3}(0001)$ and $\mathrm{KFe}_{\mathrm{X}} \mathrm{O}_{\mathrm{y}}(111)$ 
model catalyst films by TDS. As for water on $\mathrm{Fe}_{3} \mathrm{O}_{4}(111)$, the sequential adsorption of chemisorbed $\gamma$ species, physisorbed $\beta$ species, and condensed $\alpha$ multilayers is observed on all three surfaces. This can be seen in Fig. 11, which shows TD spectra measured after exposing a $\mathrm{KFe}_{\mathrm{X}} \mathrm{O}_{\mathrm{Y}}(111)$ film to the indicated amounts of $\mathrm{EB}$ (a) and styrene (b) at $100 \mathrm{~K}$. For the smallest exposure both chemisorbed $\gamma$-EB and $\gamma$-styrene desorb at $260 \mathrm{~K}$. Their saturation exposures are about $1 \mathrm{~L}$. The respective spectra for $\mathrm{Fe}_{3} \mathrm{O}_{4}(111)$ and $\alpha-\mathrm{Fe}_{2} \mathrm{O}_{3}(0001)$ look similar and are presented elsewhere, the saturation exposures thereon are also $1 \mathrm{~L}$. The desorption peak for physisorbed $\beta$-EB appears at $230 \mathrm{~K}$ and shifts with increasing exposure to $206 \mathrm{~K}$, then the condensed $\alpha$-EB multilayer peak appears at $155 \mathrm{~K}$. The peak for physisorbed $\beta$-styrene shifts from $238 \mathrm{~K}$ to $215 \mathrm{~K}$, then the condensed $\alpha$-St multilayer peak appears at $170 \mathrm{~K}$. The desorption temperatures of the condensed species agree well with their respective heats of sublimation ${ }^{57}$.

An exposure of $1 \mathrm{~L}$ of EB or St at a gas temperature of $300 \mathrm{~K}$ corresponds to $1.96 \times 10^{14}$ molecules $\mathrm{cm}^{-2}$ impinging onto the surface. The van-der-Waals area of EB and styrene molecules lying flat on the surface is approximately $50 \AA^{2}$, so that $1 \mathrm{ML}$ corresponds to $\mathrm{N}=2 \times 10^{14}$ molecules $\mathrm{cm}^{-2}$, assuming a densely packed layer. Since condensation occurs at $150 \mathrm{~K}$ for these molecules, a sticking probability of 1 can be assumed for the sample temperature of $100 \mathrm{~K}$ during adsorption, so that the observed saturation exposure of the chemisorbed $\gamma$ species of $1 \mathrm{~L}$ corresponds to about $1 \mathrm{ML}$. Thus, the chemisorption sites do not represent a minority species as would be expected for surface defects, although surface defects can also contribute to the desorption signals.

Fig. 12 compares TD spectra after applying small exposures of EB and St to the three substrates, so that only the $\gamma$ chemisorption states get populated. On $\mathrm{Fe}_{3} \mathrm{O}_{4}(111)$, St is bound condsiderably more strongly than EB. On $\alpha-\mathrm{Fe}_{2} \mathrm{O}_{3}(0001)$, two chemisorbed species are observed for EB and St. A minority species labeled $\gamma_{2}$ creates desorption peaks around $370 \mathrm{~K}$, for which saturation coverages of less than $0.1 \mathrm{ML}$ were deduced. The desorption peaks of the main chemisorption species appear at lower temperatures and are labeled $\gamma_{1}$. Here again St is bound more strongly than EB, but the difference is smaller when compared to $\mathrm{Fe}_{3} \mathrm{O}_{4}(111)$. On $\mathrm{KFe}_{\mathrm{x}} \mathrm{O}_{\mathrm{y}}(111)$, the desorption temperatures of $\gamma \mathrm{EB}$ and $\mathrm{St}$ are equal and quite low. From the TDS data the desorption energies and frequency factors of the chemisorbed species were determined by a threshold analysis $^{58}$ (with the exception of the minority species $\gamma_{2}$ on $\mathrm{Fe}_{2} \mathrm{O}_{3}$ ). They are listed in table 1 . The desorption energies turn out quite reasonably and most of the frequency factors have reasonable values in the range $10^{11}-10^{13} \mathrm{~s}^{-1}$. Usually, frequency factors contain large uncertainties when determined by TDS and the value $2 \times 10^{15} \mathrm{~s}^{-1}$ for $\mathrm{EB}$ on $\mathrm{Fe}_{3} \mathrm{O}_{4}(111)$ is definitely too high. As we have discussed before for this system, this is probably due to a not strictly sequential adsorption of $\gamma$ - and $\beta$-EB at the low adsorption temperature of $100 \mathrm{~K}^{22}$.

The Langmuir isotherm gives the relative coverage $\Theta_{\mathrm{r}}$ (number of occupied divided by the number of available adsorption sites) under adsorption-desorption equilibrium conditions ${ }^{59}$ :

$$
\Theta_{\mathrm{r}}=b p /(1+b \mathrm{p})
$$

with $\mathrm{p}$ being the gas pressure and $\mathrm{b}$ given by

$$
\mathrm{b}=\left\{\mathrm{s}_{0} /\left(\mathrm{v}_{\mathrm{des}} \mathrm{N}(2 \pi \mathrm{mkT})^{0.5}\right)\right\} \exp \left\{-\left(\Delta \mathrm{E}_{\mathrm{ad}}-\Delta \mathrm{E}_{\mathrm{des}}\right) / \mathrm{kT}\right\} .
$$

Here, $\mathrm{s}_{0}$ is the initial sticking coefficient, $v_{\mathrm{des}}$ the frequency factor for desorption, $\mathrm{N}$ the adsorption site density which is $2 \times 10^{14} \mathrm{~cm}^{-2}$ for $\mathrm{EB}$ and $\mathrm{St}, \mathrm{m}$ the mass of the adsorbing molecule, $\mathrm{k}$ the Boltzmann constant, $\mathrm{T}$ the temperature, and $\Delta \mathrm{E}_{\mathrm{ad}}$, $\Delta \mathrm{E}_{\mathrm{des}}$ the activation energies for adsorption and desorption, respectively. The Langmuir formalism assumes that sticking occurs only on unoccupied sites without mobile precursor states. Although we observe a precursor adsorption kinetics at $\mathrm{T}=100 \mathrm{~K}^{22}$, the lifetime and diffusion lenght of the precursor species become very small at $\mathrm{T}=900 \mathrm{~K}$, so that one can assume Langmuir adsorption kinetics at such high temperatures. For competitive coadsorption of two different molecules A and B, we obtain

$\Theta_{\mathrm{r}, \mathrm{A}}=\mathrm{b}_{\mathrm{A}} \mathrm{p}_{\mathrm{A}} /\left(1+\mathrm{b}_{\mathrm{A}} \mathrm{p}_{\mathrm{A}}+\mathrm{b}_{\mathrm{B}} \mathrm{p}_{\mathrm{B}}\right), \quad \Theta_{\mathrm{r}, \mathrm{B}}=\mathrm{b}_{\mathrm{B}} \mathrm{p}_{\mathrm{B}} /\left(1+\mathrm{b}_{\mathrm{A}} \mathrm{p}_{\mathrm{A}}+\mathrm{b}_{\mathrm{B}} \mathrm{p}_{\mathrm{B}}\right)$, and $\Theta_{\mathrm{r}}=\Theta_{\mathrm{r}, \mathrm{A}}+\Theta_{\mathrm{r}, \mathrm{B}}$.

Here, $\mathrm{p}_{\mathrm{A}}$ and $\mathrm{p}_{\mathrm{B}}$ are the partial pressures of gases $\mathrm{A}$ and $\mathrm{B}$, respectively.

For estimating the surface coverages of $\mathrm{EB}$ and $\mathrm{St}$ under the technical styrene synthesis reaction conditions $(\mathrm{T}=873 \mathrm{~K}, \mathrm{pEB}$ or $\mathrm{pSt}=200 \mathrm{mbar}$ ), we assume initial sticking coefficients $\mathrm{s}_{0}=1$ for both molecules and non-activated adsorption $\left(\Delta \mathrm{E}_{\mathrm{ad}} \approx 0\right)$. We use the $\Delta \mathrm{E}_{\mathrm{des}}$ values from table 1 , but, because of the uncertain frequency factors, we use a constant value $v_{\mathrm{des}}=10^{13} \mathrm{~s}$ 1 for both gases on all substrates. First we consider the adsorption of only EB and only St (no coadsorption). It turns out that the physisorbed $\beta$ states are occupied by less than $1 \%$. The relative coverages $\Theta_{\mathrm{r}}$ of the chemisorbed $\gamma$ states of EB (St) would be $71 \%(99 \%)$ on $\mathrm{Fe}_{3} \mathrm{O}_{4}(111), 6 \%(17 \%)$ on $\alpha-\mathrm{Fe}_{2} \mathrm{O}_{3}(0001)$ (majority species $\left.\gamma_{1}\right)$ and $6 \%(6 \%)$ on $\mathrm{KFe}_{\mathrm{x}} \mathrm{O}_{\mathrm{y}}(111)$. The more strongly bound $\gamma_{2}$ minority species on $\mathrm{Fe}_{2} \mathrm{O}_{3}$ are always fully occupied, but for the following discussion of the coadsorption of EB and St we neglect its contribution because the number of sites is only $9 \%$ of the $\gamma_{1}$ sites.

For the competitive coadsorption of $\mathrm{EB}$ and $\mathrm{St}$ we assume equal partial pressures of $100 \mathrm{mbar}$ each. The Langmuir extrapolation yields on $\mathrm{Fe}_{3} \mathrm{O}_{4}(111) \Theta_{\mathrm{r}}=\Theta_{\mathrm{r}, \mathrm{EB}}+\Theta_{\mathrm{r}, \mathrm{ST}}=98 \%$ and $\Theta_{\mathrm{EB}} / \Theta_{\mathrm{ST}} \approx 0.02$; on $\alpha-\mathrm{Fe}_{2} \mathrm{O}_{3}(0001) \Theta_{\mathrm{r}}=12 \%$ and 
$\Theta_{\mathrm{EB}} / \Theta_{\mathrm{ST}} \approx 0.3$, and on $\mathrm{KFe}_{\mathrm{X}} \mathrm{O}_{\mathrm{y}}(111) \Theta_{\mathrm{r}}=6 \%$ and $\Theta_{\mathrm{EB}} / \Theta_{\mathrm{ST}} \approx 1$. Thus on $\mathrm{Fe}_{3} \mathrm{O}_{4}(111) 98 \%$ of all chemisorption sites are occupied, on $\mathrm{Fe}_{2} \mathrm{O}_{3}(0001) 12 \%$, and on $\mathrm{KFe}_{\mathrm{x}} \mathrm{O}_{\mathrm{y}}(111) 6 \%$. For the catalytic dehydrogenation reaction of EB to St the relative occuppation of these sites by $\mathrm{EB}$ and $\mathrm{St}$ given by $\Theta_{\mathrm{EB}} / \Theta_{\mathrm{ST}}$ is important. On $\mathrm{Fe}_{3} \mathrm{O}_{4}$ almost all chemisorption sites are blocked by the product molecule styrene, on $\mathrm{Fe}_{2} \mathrm{O}_{3} 2 / 3$ of these sites are occupied by styrene, and on $\mathrm{KFe}_{\mathrm{X}} \mathrm{O}_{\mathrm{y}}$ only half of them are occupied by styrene. This suggests an increasing catalytic activity when going from $\mathrm{Fe}_{3} \mathrm{O}_{4}$ over $\mathrm{Fe}_{2} \mathrm{O}_{3}$ to $\mathrm{KFe}_{\mathrm{x}} \mathrm{O}_{\mathrm{y}}$, which indeed was observed in recent reactivity studies performed over the unpromoted $\mathrm{Fe}_{3} \mathrm{O}_{4}(111)$ and $\alpha-\mathrm{Fe}_{2} \mathrm{O}_{3}(0001)$ films at elevated gas pressures ${ }^{24}$. There, $\mathrm{Fe}_{3} \mathrm{O}_{4}(111)$ was found to be inactive and $\mathrm{Fe}_{2} \mathrm{O}_{3}(0001)$ films with high surface defect concentrations were active, which bridges the pressure gap for these model systems. Furthermore, kinetic experiments performed by Hirano over polycrystalline iron oxide catalyst samples in the mbar range revealed potassium promoted samples to be 10 times more active than unpromoted $\mathrm{Fe}_{2} \mathrm{O}_{3}{ }^{5}$. The adsorption-desorption equilibrium constants for the educt and product molecules EB and St obtained from modelling these experiments with simple rate equations were in qualitative agreement with the ones obtained from the TDS data in this work. This bridges the material-pressure gap from the single crystalline model systems to polycrystalline catalyst samples, and it indicates that the single crystalline iron oxide films represent realistic model systems for technical styrene synthesis catalysts.

\section{Conclusions}

Well ordered epitaxial $\mathrm{FeO}(111), \mathrm{Fe}_{3} \mathrm{O}_{4}(111), \alpha-\mathrm{Fe}_{2} \mathrm{O}_{3}(0001)$, and potassium iron oxide films with a surface composition close to $\mathrm{KFeO}_{2}$ were grown onto $\mathrm{Pt}(111)$. On $\mathrm{FeO}(111)$ an oxygen-terminated surface structure is formed, the other three oxides form surface structures terminated by metal cations if prepared in oxygen partial pressures around $10^{-6}$ mbar. The adsorption studies clearly reveal a specific interaction of water with the iron terminated $\mathrm{Fe}_{3} \mathrm{O}_{4}(111)$ surface, whereas the purely oxygen terminated $\mathrm{FeO}(111)$ surface is chemically inert. The dissociative chemisorption of water becomes possible by the cooperative action of an acidic iron and a neighboring basic oxygen site. On $\mathrm{Fe}_{3} \mathrm{O}_{4}(111)$ these sites are located in a distance from each other that fits to the geometry of the water molecule, so that $\mathrm{OH}^{\delta-}$ can adsorb onto an $\mathrm{Fe}$ site and $\mathrm{H}^{\delta+}$ onto a neighboring oxygen site immediately after the dissociation. The cooperative action of acidic and basic sites arranged in a way that fits the geometry of the reactant molecule most likely plays a key role for many surface reactions on metal oxides, like dehydrogenations and others. Regarding the catalytic dehydrogenation of ethylbenzene to styrene, the TDS experiments reveal desorption energies for the ethylbenzene educt and styrene product molecules which suggest an increasing catalytic activity when going from $\mathrm{Fe}_{3} \mathrm{O}_{4}(111)$ over $\alpha-\mathrm{Fe}_{2} \mathrm{O}_{3}(0001)$ to $\mathrm{KFe}_{\mathrm{x}} \mathrm{O}_{\mathrm{y}}(111)$. This result is in line with kinetic experiments performed at elevated gas pressures over polycrystalline catalyst samples and over the epitaxial model systems presented here. It bridges the pressure-material gap and demonstrates that the single crystalline iron oxide films model technical styrene synthesis catalysts in a realistic way.

\section{Acknowledgements:}

We thank Robert Schlögl for fruitful discussions and Manfred Swoboda for technical assistence. Y. Joseph acknowledges financial support from the Deutsche Forschungs-gemeinschaft.

\section{References:}

V.E. Henrich and P.A. Cox, The Surface Science of Metal Oxides, Cambridge Univ. Press, Cambridge 1994

J.W. Geus; Appl. Catalysis, 1986, 25, 313.

E.H. Lee; Catal. Rev., 1973, 8, 285.

K. Kochloefl, in Handbook of Heterogeneous Catalysis, ed.: G. Ertl, H. Knözinger, J. Weitkamp; Wiley-VCH, Weinheim,1997,Vol.

5, p. 2151

T. Hirano; Appl. Catal., 1986, 26, 65

T. Hirano; Appl. Catal., 1986, 28, 119.

K. Coulter, D.W. Goodman, R.G. More; Catal. Lett., 1995, 31, 1.

M. Muhler, J. Schütze, M. Wesemann, T. Rayment, A. Dent, R. Schlögl and G. Ertl; J. Catal., 1990, $126,339$.

M Muhler, R. Schlögl and G. Ertl; J. Catal., 1992, 138, 413.

D. Schmalzried, Chemical Kinetics of Solids, VCH, Weinheim, 1995.

Y.J. Kim, Y. Gao and S.A. Chambers; Surf. Sci., 1997, 371, 358.

Y. Gao, Y.K. Kim, S. Thevuthasan, and S.A. Chambers; J. Appl. Phys., 1997, 81, 3253.

G.H. Vurens, M. Salmeron and G.A. Somorjai; Surf. Sci., 1988, 201, 129.

H.C. Galloway, J.J. Benitez and M. Salmeron; Surf. Sci., 1993, 298, 127.

H.C. Galloway, P. Sautet and M. Salmeron; Phys. Rev. B, 1996, 54, R11145.

W. Weiss, A. Barbieri, M.A. VanHove, and G.A. Somorjai; Phys. Rev. Lett., 1993, 71, 1848.

A. Barbieri, W. Weiss, M.A. Van Hove, G.A. Somorjai ; Surf. Sci., 1994, 302, 259.

M. Ritter, W. Ranke and W. Weiss; Phys. Rev. B, 1998, 57, 7240.

W. Weiss and M. Ritter, Phys. Rev. B, 1999, 50, 5201.

Sh. K. Shaikhudtinov and W. Weiss, Surf. Sci. Lett. 1999, in press.

M. Ritter and W. Weiss; submitted to Surf. Sci. 1999.

D. Zscherpel, W. Ranke, W. Weiss, and R. Schlögl, J. Chem. Phys., 1998, 108, 9506.

W., Ranke and W. Weiss, Surf. Sci., 1998, 414, 238.

W. Weiss, D. Zscherpel and R. Schlögl; Catal. Lett., 1998, 52, 215.

W. Weiss, M. Ritter, D. Zscherpel, M. Swoboda and R. Schlögl; J. Vac. Sci. Technol. A, 1998, 16, 21. 
U. Scheithauer, G. Meyer and M. Henzler; Surf. Sci., 1986, 178, 441.

F. Nakao, Vacuum, 1975, 25, 431.

Y.J. Kim, C. Westphal, R.X. Ynzunza, H.C. Galloway, M. Salmeron, M.A. Van Hove and C.S. Fadley; Phys. Rev. B, 1997, 55, R13448.

R.W.G. Wyckoff, Crystal Structures, 2nd ed., Vol. I, Interscience Publishers, 1982, p.85.

R.M. Cornell and U. Schwertmann, The Iron Oxides, VCH, Weinheim, 1996.

X.-G. Wang and M. Scheffler, priv. comm..

X.-G. Wang, W. Weiss, Sh.K. Shaikhutdinov, M. Ritter, M. Petersen, F. Wagner, R. Schlögl and M. Scheffler; Phys. Rev. Lett., $1998, \mathbf{8 1}, 1038$

L.E. Davis, N.C. MacDonald, P.W. Palmberg, P.E. Riach and R.E. Weber, Handbook of Auger electron spectroscopy, Physical Electronics Industries, Inc., Eden Prairie, Minnesota, 1976.

Z. Tomkowicz and A. Szytuka, J. Phys. Chem. Solids, 1977, 38, 1117.

R.D. Diehl and R. McGrath, Surf. Sci. Rep., 1996, 23, 43.

J. Nerlov, S.V. Hoffmann, M. Shimomura and P.J. Moeller, Surf. Sci., 1998, 401, 56.

R. Schuster, J.V. Barth, G. Ertl, and R.J. Behm, Phys. Rev. Lett., 1992, 69, 2547.

P.W. Murray, D. Abrooks, F.M. Leibsle, R.D. Diehl, R. McGrath, Surf. Sci., 1994, 314, 307.

P.W. Murray, N.G. Condon, and G. Thornton, Surf. Sci., 1995, 323, L281.

N.D. Lang, Phys. Rev. Lett., 1986, 56, 1164.

M.P. Seah and W.A. Dench, Surf. Interface Analysis, 1979, 1, 2.

D.W. Turner, A.D. Baker, C. Baker, and C.R. Brundle, Molecular Photoelectron Spectroscopy, Wiley-Interscience, New York, 1970.

D. Schmeisser, F.J. Himpsel, G. Hollinger, B. Reihl, and K. Jacobi, Phys. Rev. B, 1983, 27, 3279.

S. Fölsch, A. Stock, and M. Henzler; Surf. Sci., 1992, 264, 65.

K. Morokuma; J. Chem. Phys., 1971, 55, 1236.

H. Umeyama and K. Morokuma, J. Am. Chem. Soc., 1977, 99, 1316.

P.A. Thiel and T.E. Madey; Surf. Sci. Rep., 1987, 7, 211

we write $\mathrm{OH}^{\delta-}$ and $\mathrm{H}^{\delta+}$ instead of $\mathrm{OH}^{-}$and $\mathrm{H}^{+}$because a full elementary charge transfer upon chemisorption is unlikely.

R.L. Kurtz and V.E. Henrich; Phys. Rev. B, 1982, 26, 6682

R.L. Kurtz and V.E. Henrich; Surf. Sci., 1983, 129, 345.

P.B. Smith and S.L. Bernasek; Surf. Sci., 1987, 188, 241

R.J. Lad and V.E. Henrich; Surf. Sci., 1988, 193, 81.

X.D. Peng and M.A. Barteau; Surf. Sci., 1990, 233, 283.

V.A. Gercher and D.F. Cox; Surf. Sci., 1995, 322, 177.

P. Liu, T. Kendelewicz, G.E. Brown, E.J. Nelson, and S.A. Chambers, Surf. Sci., 1998, 417, 53.

M.A. Henderson, S.A. Joyce, and J.R. Rustad, Surf. Sci., 1998, 417, 66.

Landolt Börnstein, Vol.II/2a, Springer, Berlin, 1960.

E. Habenschaden and J. Küppers; Surf. Sci., 1984, 138, L147.

K. Christmann, Surface Physical Chemistry, Steinkopff, Darmstadt, 1991. 


\section{Figures and Tables:}
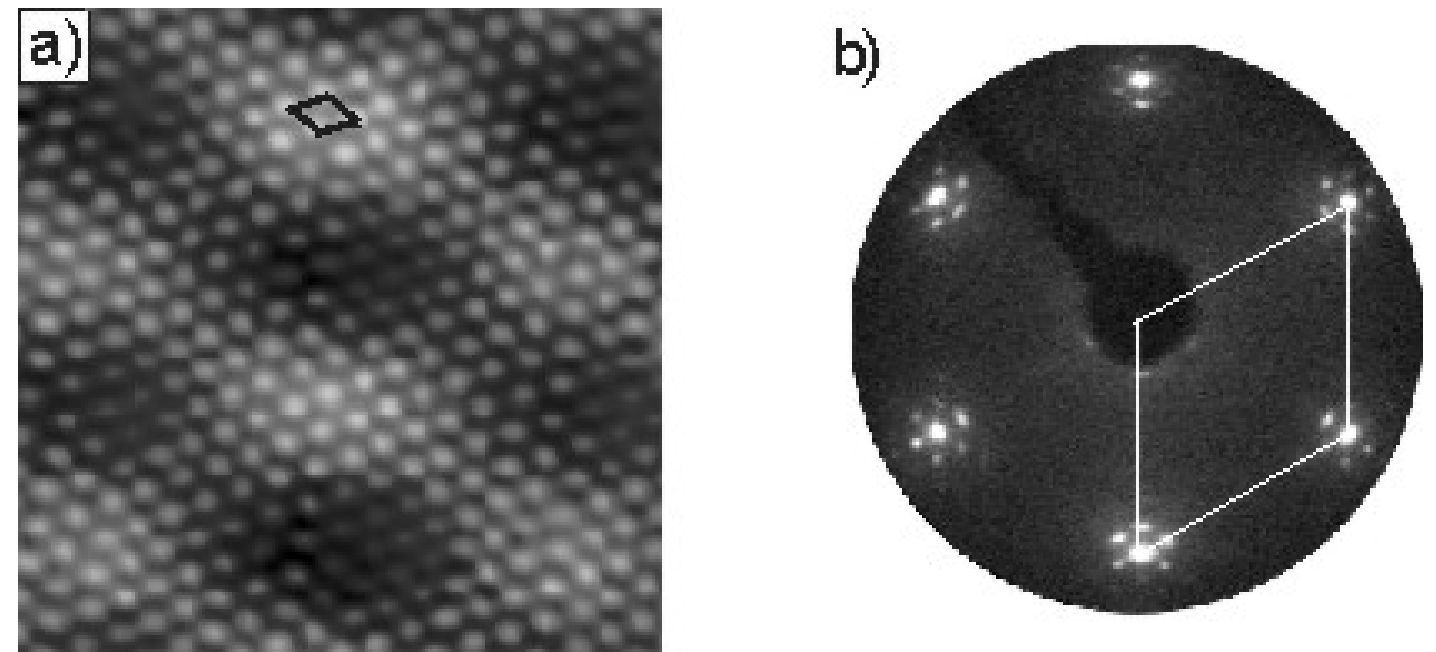

c)

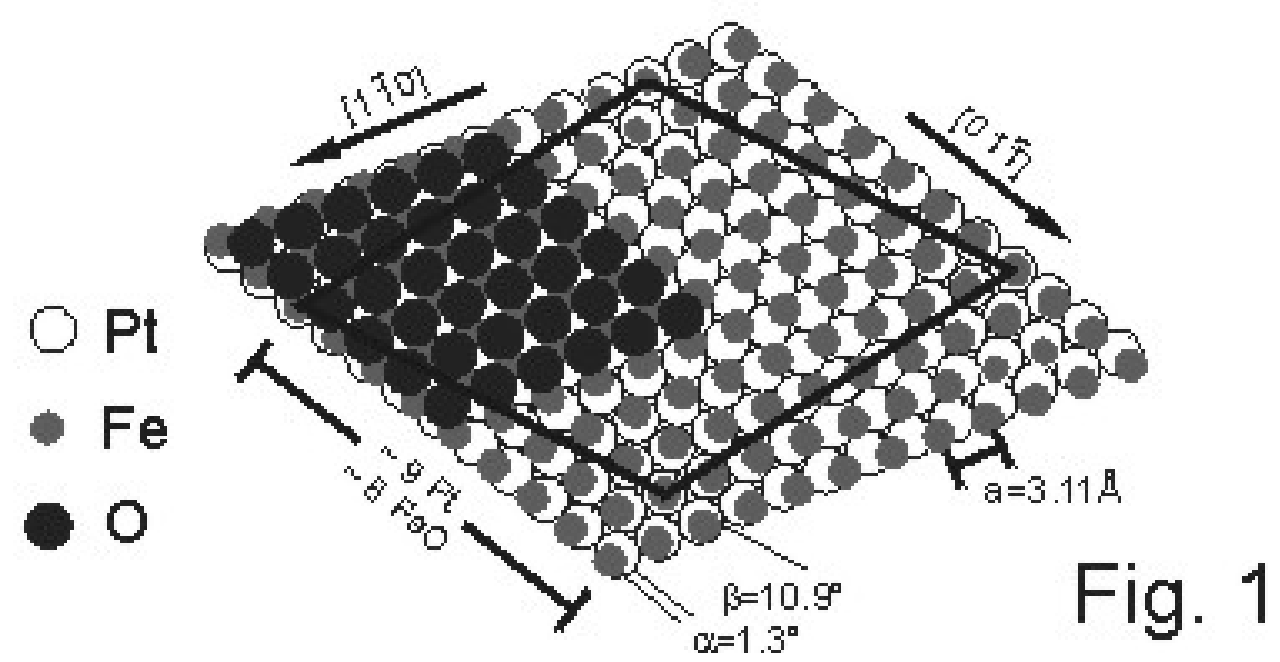

Fig. 1:

a) $55 \times 55 \AA^{2}$ STM image of a $\mathrm{FeO}(111)$ monolayer film grown onto $\mathrm{Pt}(111)$. The protrusions correspond to surface oxygen atoms forming a hexagonal lattice with the indicated unit cell, which has a lattice constant of $3.1 \AA$. The large moiré superstructure is caused by the $12 \%$ lattice mismatch to the $\mathrm{Pt}(111)$ substrate. $\mathrm{U}_{\mathrm{T}}=0.9 \mathrm{~V}, \mathrm{IT}_{\mathrm{T}}=0.3 \mathrm{nA}$.

b) LEED pattern of the $\mathrm{FeO}(111)$ monolayer film at an electron energy of $\mathrm{E}=60 \mathrm{eV}$. The main spots indicated by the reciprocal unit cell correspond to the $3.1 \AA$ periodicity on the $\mathrm{FeO}(111)-(1 \times 1)$ surface. The surrounding satellite spots are created by double diffraction between the platinum substrate and the $\mathrm{FeO}$ overlayer.

c) Model of the $\mathrm{FeO}(111)$ monolayer film. A hexagonal iron-oxygen bilayer with a lateral lattice constant of aFeO=3.10 $\AA$ is rotated by $\alpha=1.3^{\circ}$ against the platinum surface lattice. This results in the indicated large coincidence superstructure cell rotated by $\alpha+\beta$ against the $\mathrm{FeO}(111)-)-(1 \times 1)$ unit cell, which is seen in the STM image in (a). 

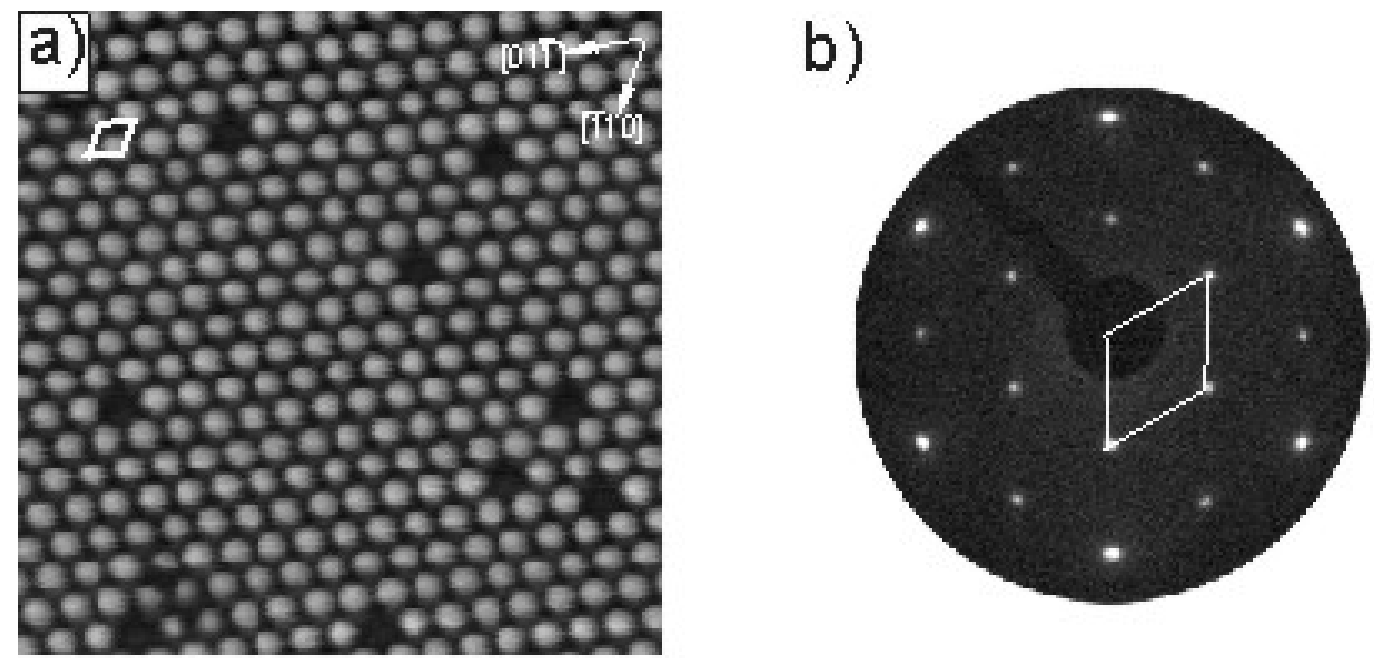

c)

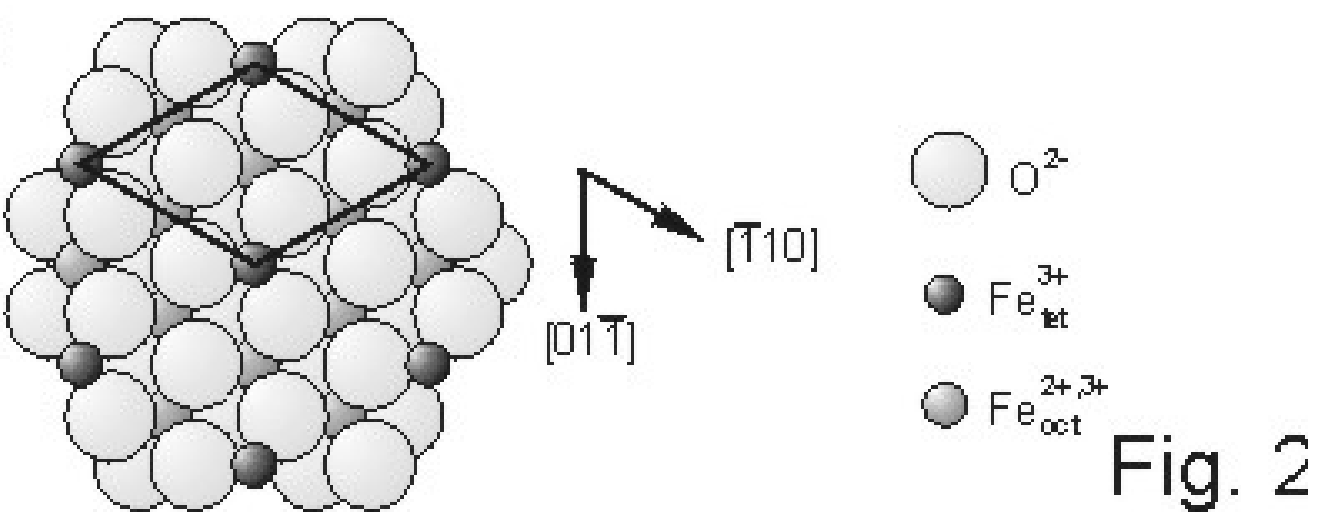

Fig. 2:

a) $90 \times 90 \AA^{2}$ STM image of the $\mathrm{Fe}_{3} \mathrm{O}_{4}(111)$ surface. The protrusions correspond to iron atoms in the topmost layer, which form a hexagonal lattice with the indicated unit cell $6 \AA$ in size. $\mathrm{U}_{\mathrm{t}}=-0.9 \mathrm{~V}, \mathrm{I}_{\mathrm{t}}=0.5 \mathrm{nA}$.

b) LEED pattern taken at $\mathrm{E}=60 \mathrm{eV}$. The indicated reciprocal unit cell corresponds to a surface periodicity of $6 \AA$.

c) Top view onto the $\mathrm{Fe}_{3} \mathrm{O}_{4}(111)$ surface structure as obtained from a dynamical LEED intensity analysis ${ }^{16}$ with the $6 \AA$ unit cell indicated. 

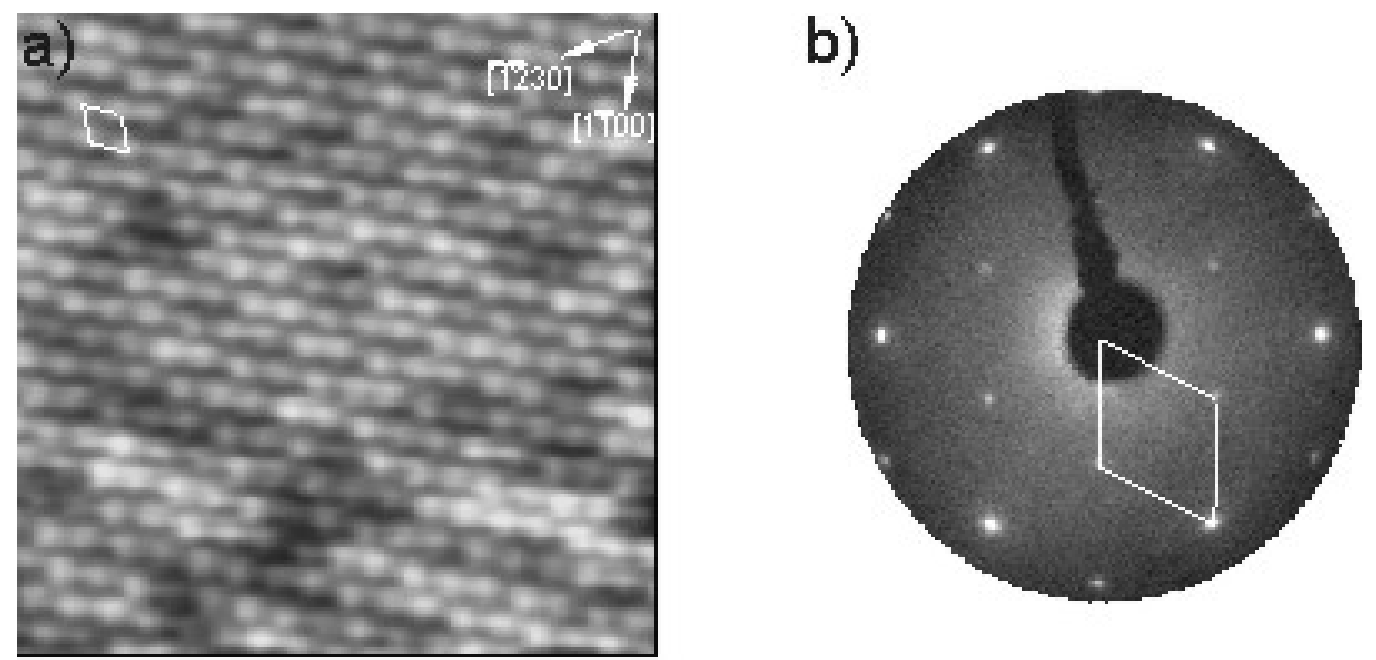

c)

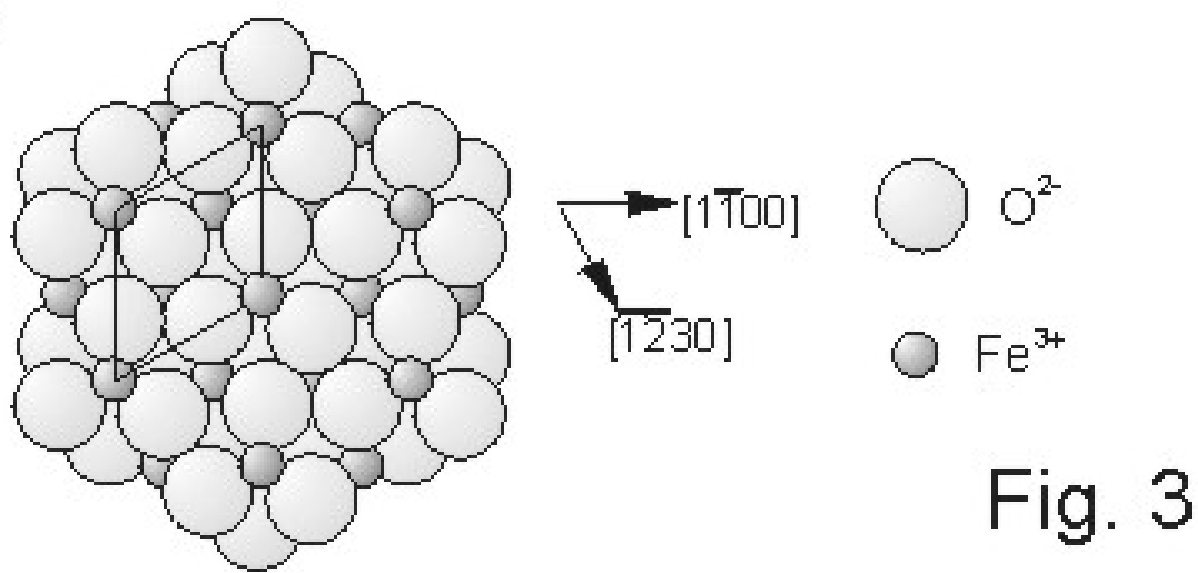

Fig. 3:

a) $120 \times 120 \AA^{2}$ STM image of an $\alpha-\mathrm{Fe}_{2} \mathrm{O}_{3}$ (0001) surface terminated by an outermost iron layer. The protrusions correspond to iron atoms in the topmost layer, which form a hexagonal surface lattice with the indicated unit cell $5 \AA$ in size. $\mathrm{U}_{\mathrm{t}}=1.3 \mathrm{~V}, \mathrm{I}_{\mathrm{t}}=1.25 \mathrm{nA}$. b) LEED pattern of this film taken at an electron energy of $60 \mathrm{eV}$, the reciprocal unit cell corresponds to a $5 \AA$ periodicity. c) Top view onto an iron-terminated $\alpha-\mathrm{Fe}_{2} \mathrm{O}_{3}(0001)$ surface with the indicated unit cell $5 \AA$ in size. 


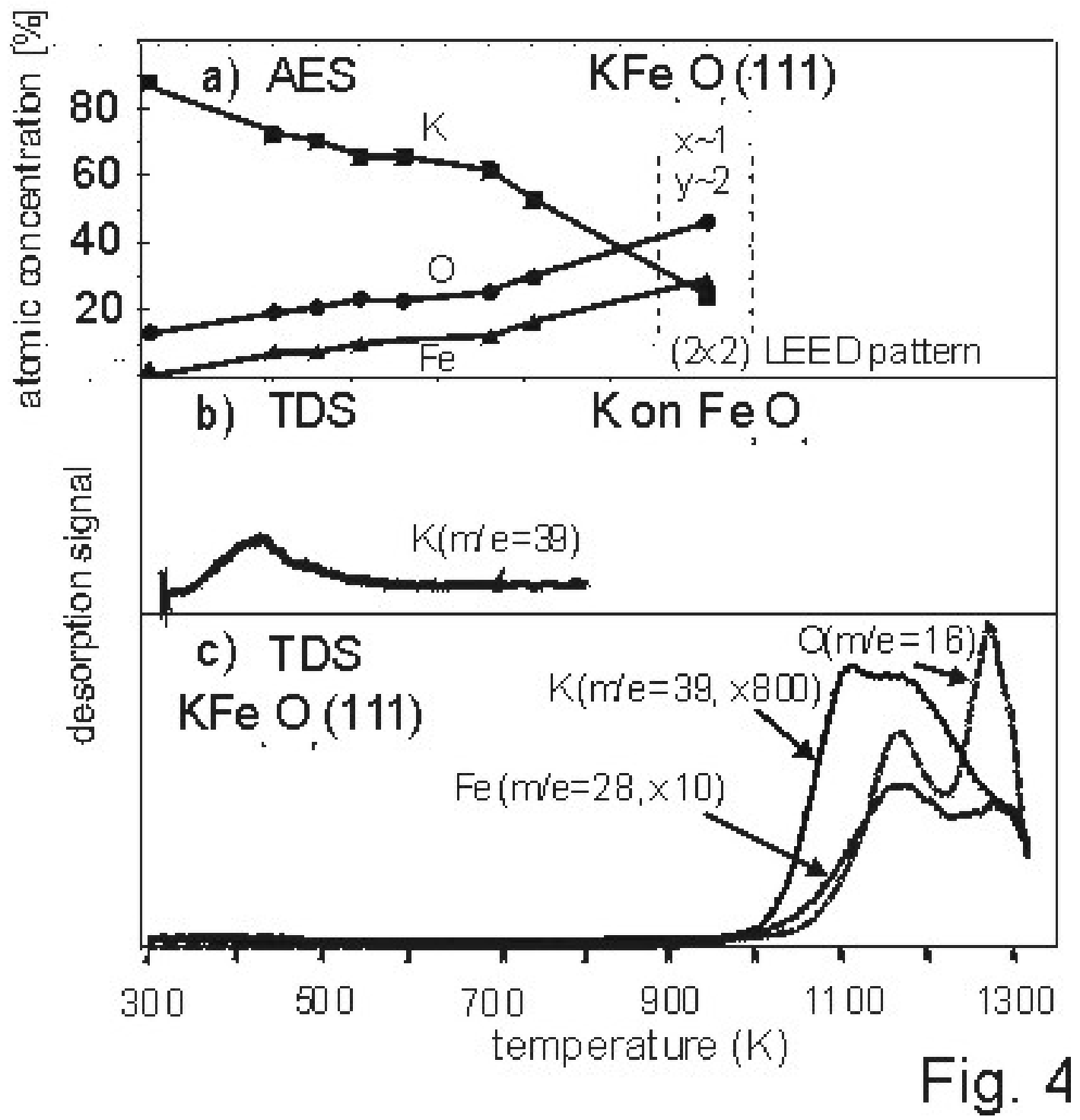

Fig. 4:

a) Surface composition (atomic concentration in percent) of an $\mathrm{Fe}_{3} \mathrm{O}_{4}(111)$ film after deposition of about $5 \mathrm{ML}$ of potassium at $300 \mathrm{~K}$ and stepwise annealing as deduced from AES data. b) Thermal desorption trace of $\mathrm{K}^{+}$after deposition of about 5 ML of potassium at $300 \mathrm{~K}$ on $\mathrm{Fe}_{3} \mathrm{O}_{4}(111)$. c) Thermal desorption traces of $\mathrm{K}^{+}, \mathrm{Fe}^{2+}$ and $\mathrm{O}^{+}$during heating up a $\mathrm{KFe}_{\mathrm{x}} \mathrm{O}_{\mathrm{y}}$ (111) film, showing the thermal decomposition of the film. 


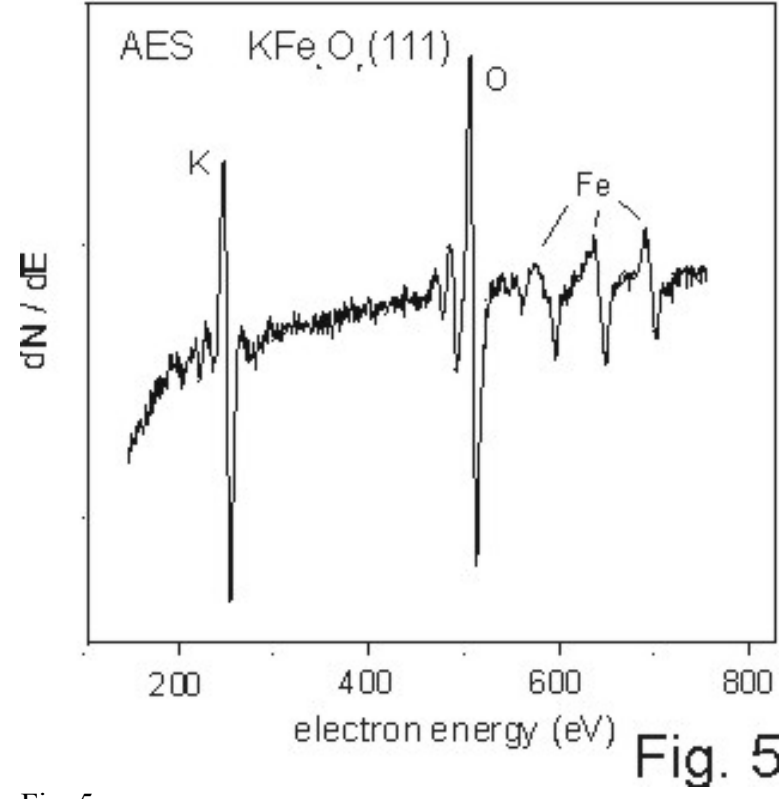

Fig. 5:

Auger electron spectrum of an ordered $\mathrm{KFe}_{\mathrm{x}} \mathrm{O}_{\mathrm{y}}(111)$ film exhibiting a (2×2) LEED pattern with respect to $\mathrm{Fe}_{3} \mathrm{O}_{4}(111)$. It corresponds to a stoichiometry close to $\mathrm{KFeO}_{2}$.
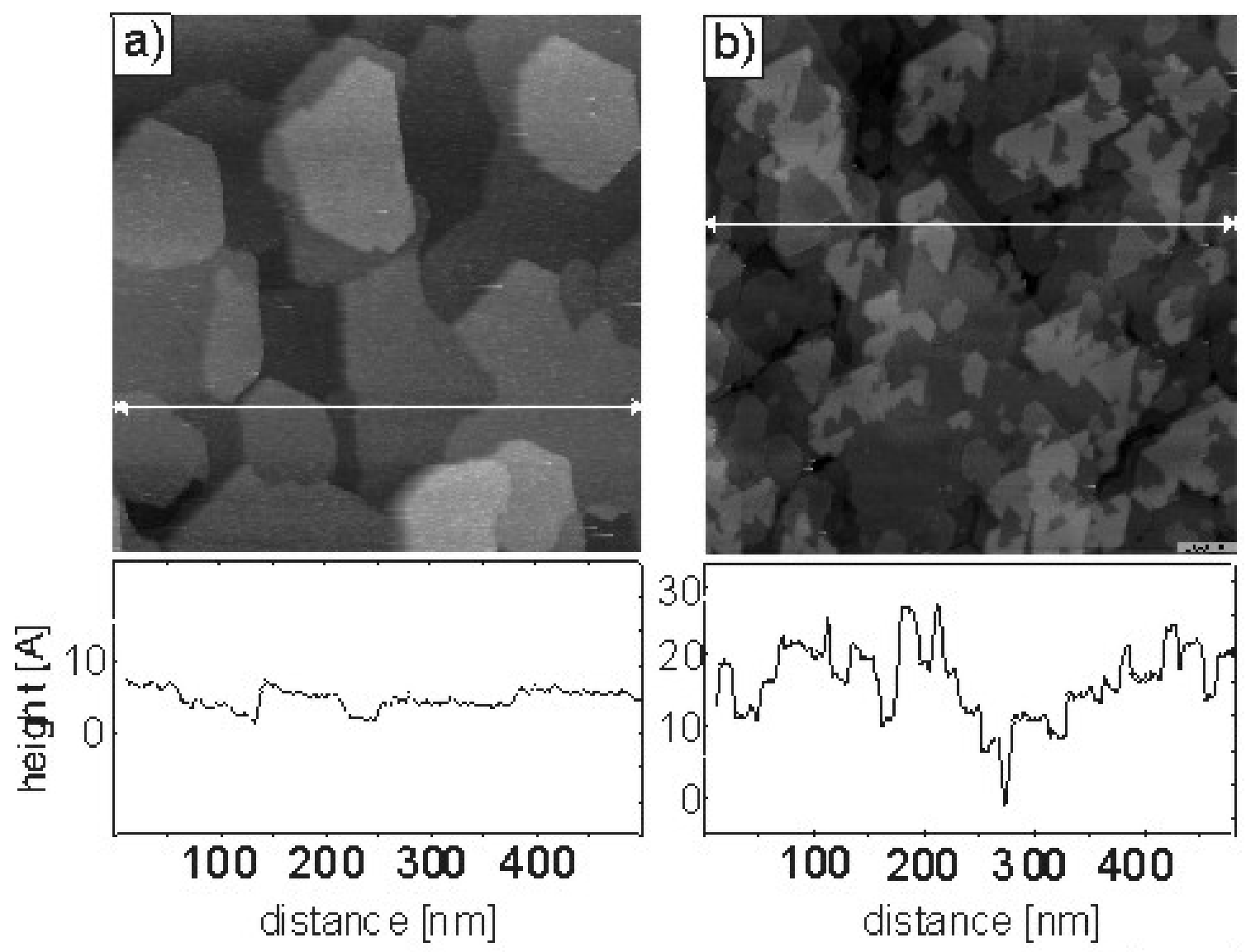

Fig. 6

Fig. 6:

$500 \times 500 \AA^{2}$ STM images of a clean $\mathrm{Fe}_{3} \mathrm{O}_{4}(111)$ (a) and of a $\mathrm{KFe}_{\mathrm{x}} \mathrm{O}_{\mathrm{y}}(111)$ film (b), showing the different surface morphologies. $\mathrm{U}_{\mathrm{t}}=0.4 \mathrm{~V}, \mathrm{I}_{\mathrm{t}}=0.6 \mathrm{nA}$. 

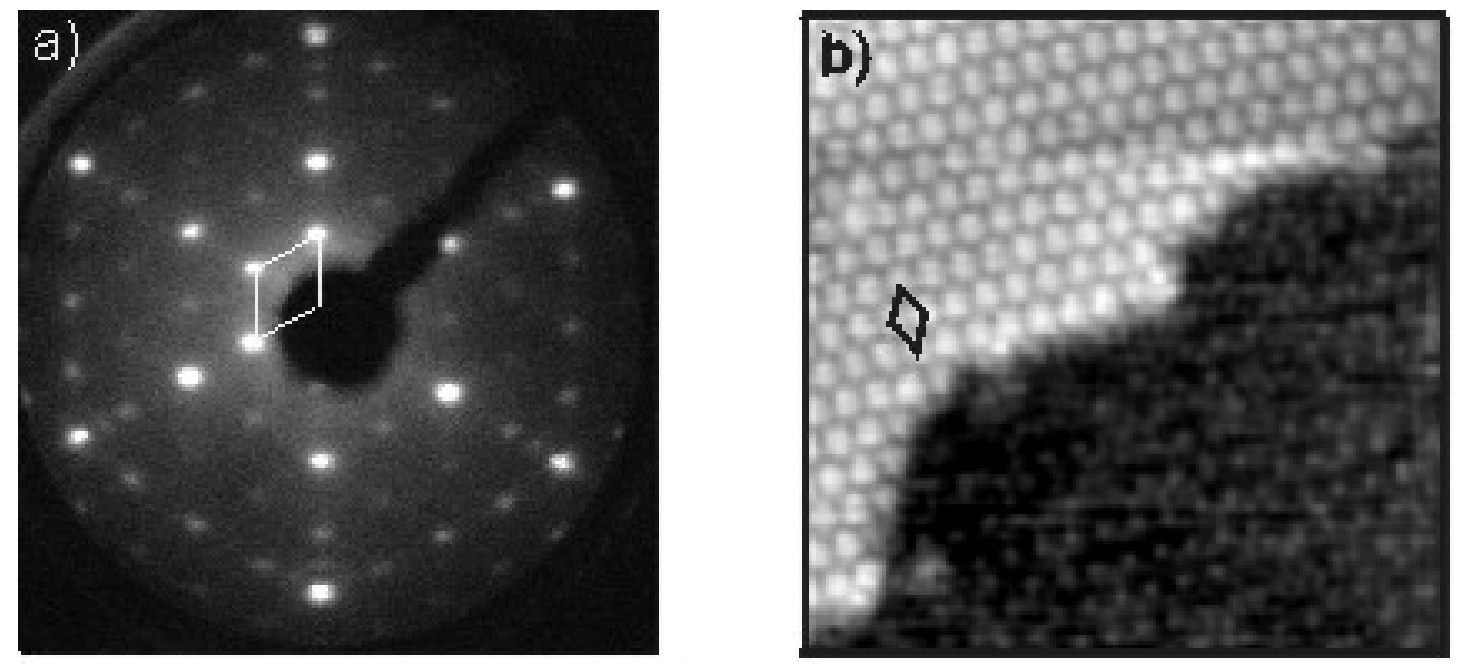

Fig. 7

Fig. 7:

(a) LEED pattern of the $\mathrm{KFe}_{\mathrm{x}} \mathrm{O}_{\mathrm{y}}(111)$ film at an electron energy of $\mathrm{E}=60 \mathrm{eV}$. The indicated reciprocal unit cell corresponds to a $(2 \times 2)$ superstructure referred to $\mathrm{Fe}_{3} \mathrm{O}_{4}(111)-(1 \times 1)$ with a surface periodicity of $12 \AA$. (b) $220 \times 220 \AA^{2}$ STM image of the $\mathrm{KFe}_{\mathrm{x}} \mathrm{O}_{\mathrm{y}}(111)$ surface. Two terraces separated by a $2.5 \AA$ high step can be seen, which both exhibit hexagonal lattices of protrusions with a $12 \AA$ periodicity. The protrusions on the upper terraces are wider than those on the lower terrace. $U_{t}=1.4$ $\mathrm{V}, \mathrm{I}_{\mathrm{t}}=1.3 \mathrm{nA}$.
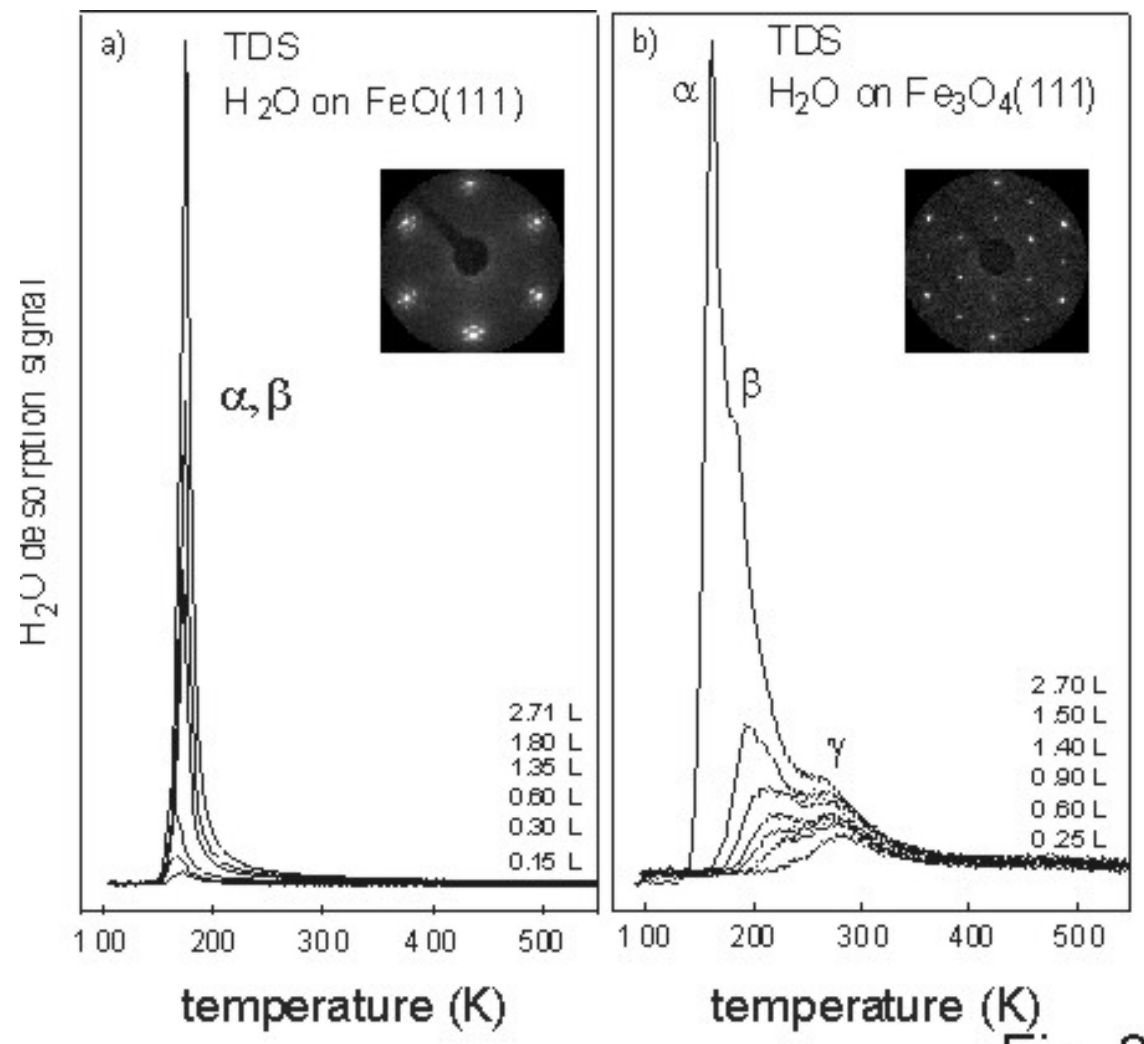

Fig. 8

Fig. 8:

Thermal desorption traces of water adsorbed onto $\mathrm{FeO}(111)$ (a) and $\mathrm{Fe}_{3} \mathrm{O}_{4}(111)$ (b). Exposures are indicated in Langmuir units. The inserts show LEED patterns of the respective clean oxide films. 


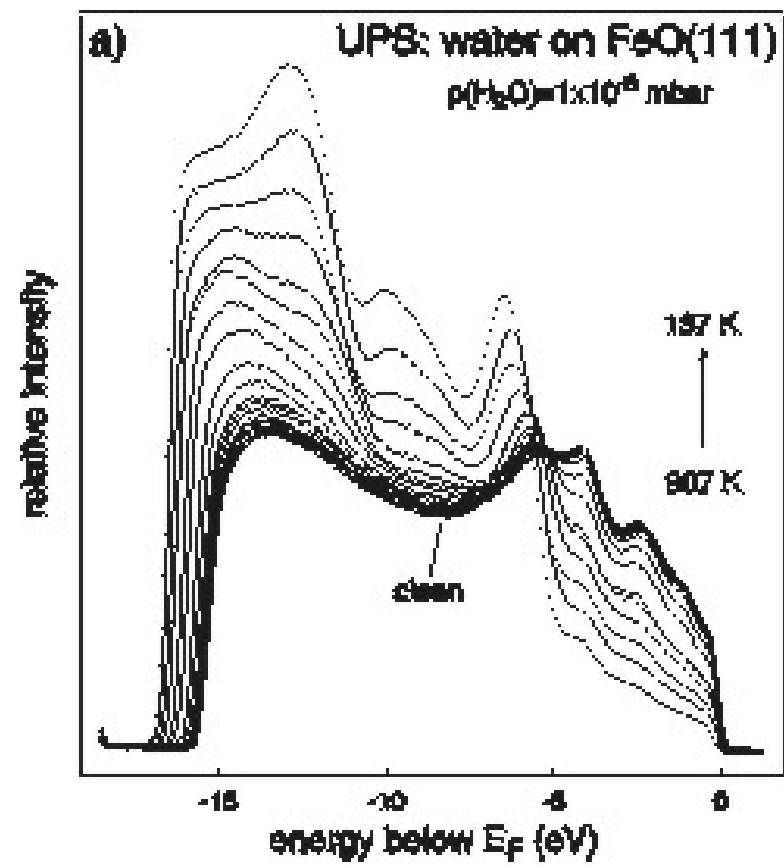

enewoy below $\mathrm{E}_{\mathrm{f}}(\mathrm{O} \mathrm{V})$

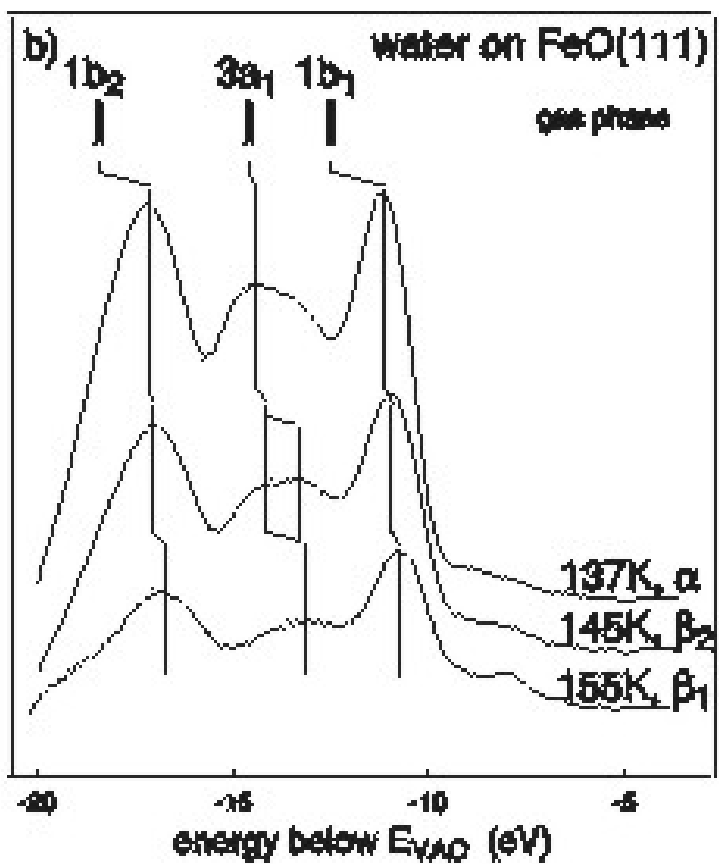

Fig. C

Fig. 9:

a) UP spectra of water adsorbed onto the $\mathrm{FeO}(111)$ surface, measured at constant pressure $\mathrm{p}\left(\mathrm{H}_{2} \mathrm{O}\right)=1 \times 10^{-8}$ mbar upon stepwise decreasing the sample temperature. The lower two dotted spectra represent saturation of two different physisorbed species $\beta_{1}$ and $\beta_{2}$, the upper dotted curve corresponds to condensation of ice $\alpha$. b) Adsorbate difference spectra corresponding to the dotted curves in (a). The energy axis refers to the vacuum level and the orbital positions for gas phase water $^{42}$ are indicated.
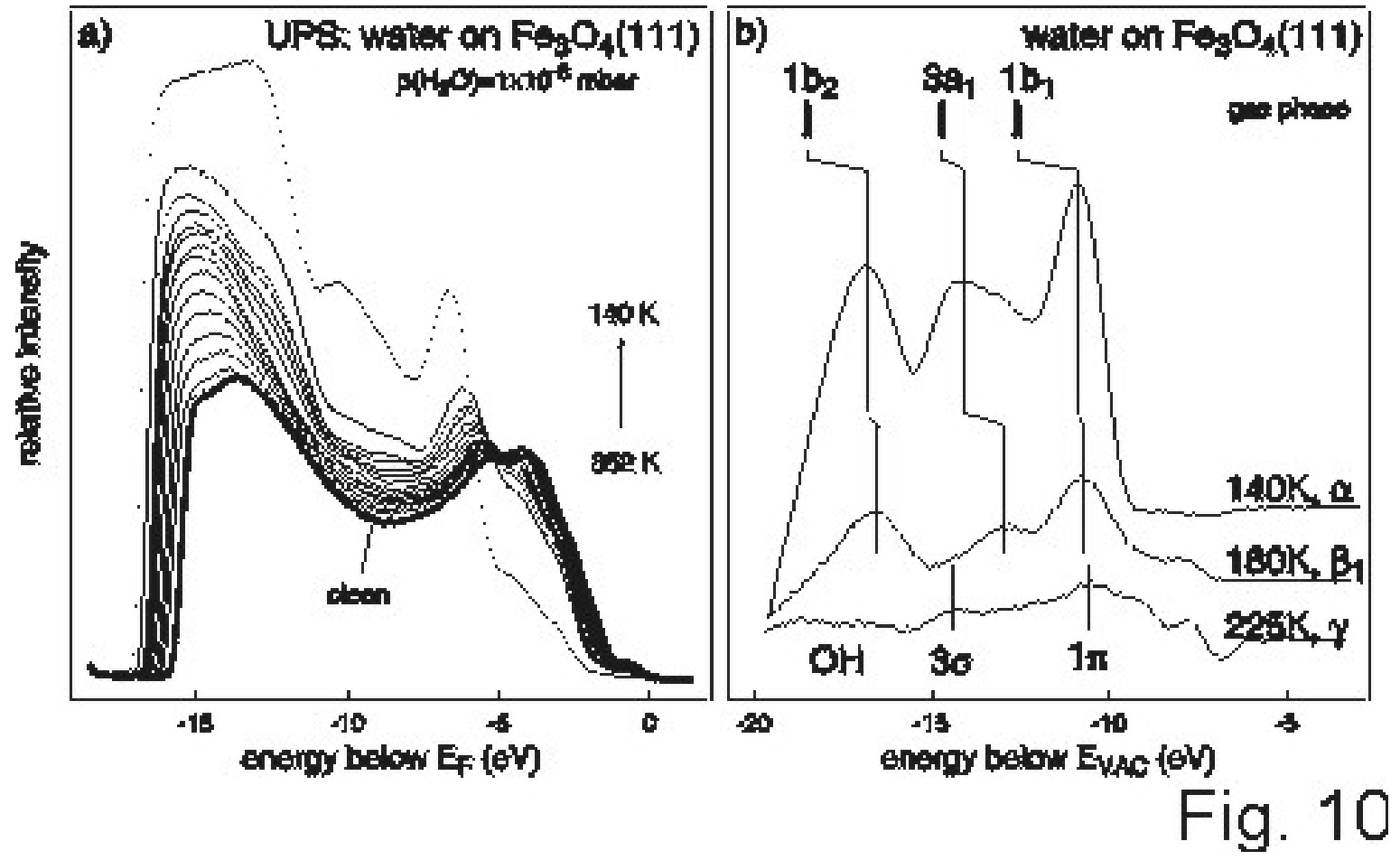

Fig. 10:

a) UP spectra of water adsorbed on the $\mathrm{Fe}_{3} \mathrm{O}_{4}(111)$ surface, measured as in Fig. 9. The lower two dotted spectra represent saturation of the chemisorbed $\gamma$ and physisorbed $\beta_{1}$ species, the upper dotted curve corresponds to condensation of ice $\alpha . b$ ) Incremental adsorbate spectra formed from the difference between the dotted curves in (a). The energy axis refers to the vacuum level and the orbital positions for gas phase water ${ }^{42}$ are in dicated. 

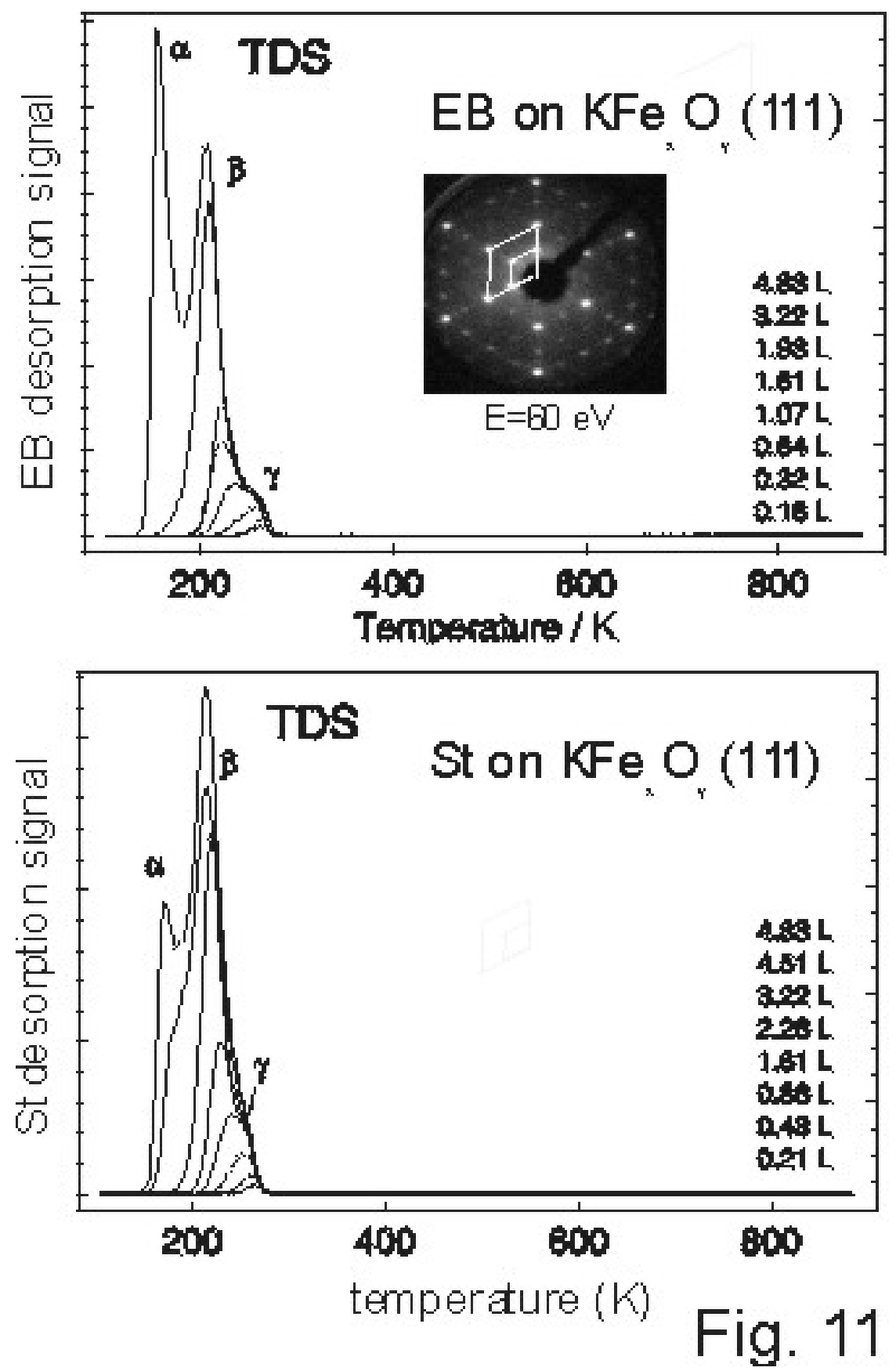

Fig. 11:

Thermal desorption traces of ethylbenzene (a) and styrene (b) adsorbed onto the $\mathrm{KFe}_{\mathrm{x}} \mathrm{O}_{\mathrm{y}}(111)$ surface. The exposures are indicated in Langmuir. The insert in (a) shows the LEED pattern of the clean surface. 

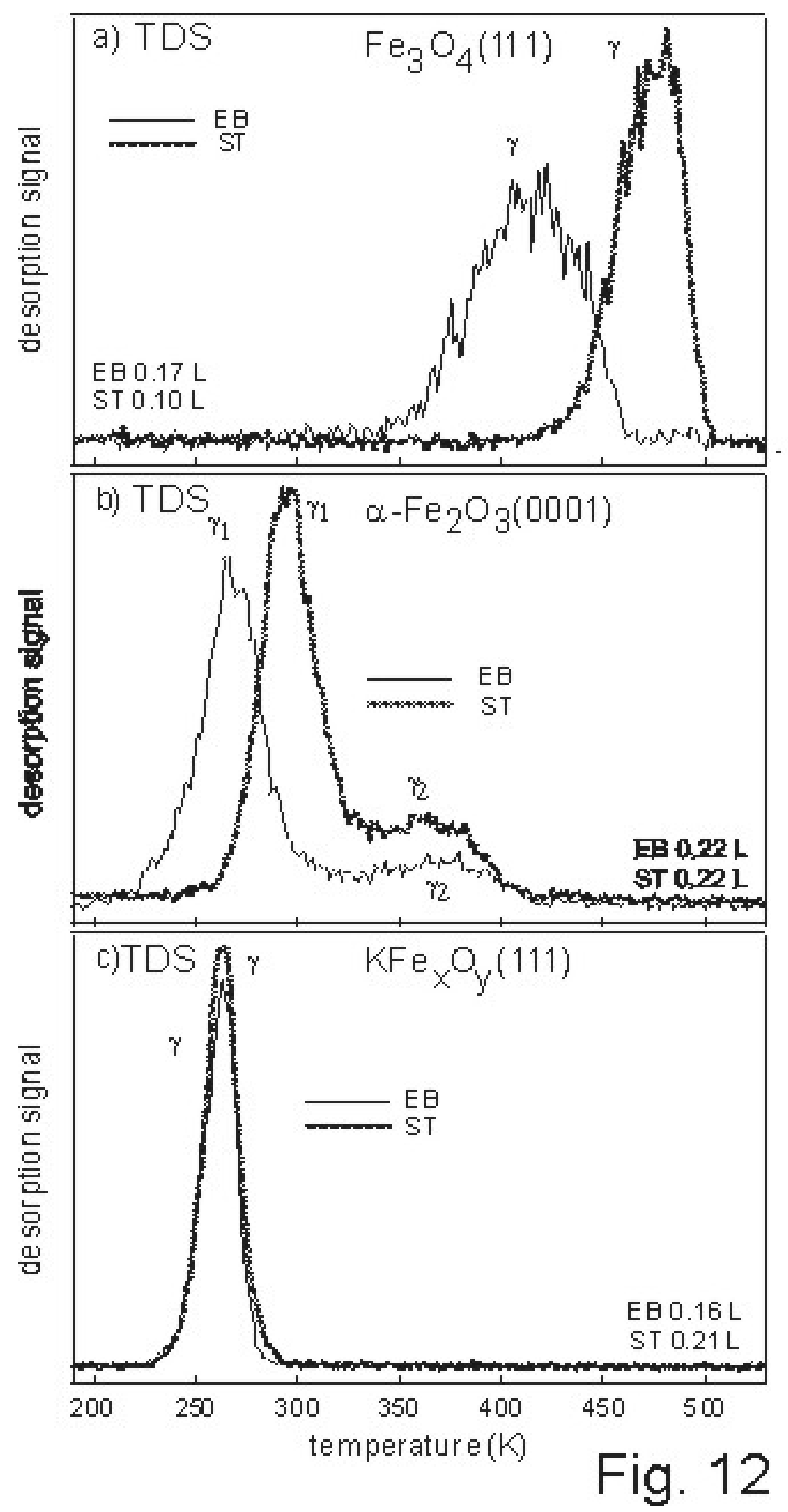

Fig. 12:

Thermal desorption traces of EB and styrene chemisorbed on $\mathrm{Fe}_{3} \mathrm{O}_{4}(111)$ (a), $\alpha-\mathrm{Fe}_{2} \mathrm{O}_{3}(0001)$ (b), and $\mathrm{KFe}_{\mathrm{X}} \mathrm{O}_{\mathrm{y}}(111)(\mathrm{c})$, taken after small exposures. 


\begin{tabular}{|c|c|c|c|c|c|c|}
\hline \multirow{3}{*}{$\mathrm{E}_{\mathrm{des}}(\mathrm{kJ} / \mathrm{mol})$} & \multicolumn{2}{|c|}{$\mathrm{Fe}_{3} \mathrm{O}_{4}(111)$} & \multicolumn{2}{|c|}{$\alpha-\mathrm{Fe}_{2} \mathrm{O}_{3}(0001)$} & \multicolumn{2}{|c|}{$\mathrm{KFe}_{\mathbf{x}} \mathrm{O}_{\mathbf{y}}(111)$} \\
\hline & ethylbenzen & & ethylbenzen & & ethylbenzene & \\
\hline & 91 & 118 & 64 & 73 & 65 & 65 \\
\hline$v_{\text {des }}\left(s^{-1}\right)$ & $2 \times 10^{15}$ & $3 \times 10^{11}$ & $1 \times 10^{12}$ & $5 \times 10^{12}$ & $2 \times 10^{12}$ & $1 \times 10^{13}$ \\
\hline
\end{tabular}

Table 1:

Desorption energies $\mathrm{E}_{\mathrm{des}}$ and frequency prefactors $v_{\mathrm{des}}$ for ethylbenzene and styrene chemisorbed on $\mathrm{Fe}_{3} \mathrm{O}_{4}(111), \alpha-$ $\mathrm{Fe}_{2} \mathrm{O}_{3}(0001)$ and $\mathrm{KFe}_{\mathrm{x}} \mathrm{O}_{\mathrm{y}}(111)$ as determined from the TDS measurements. 